\title{
Eye-hand coordination: cooperative and competitive systems?
}

Citation for published version (APA):

Bekkering, H. (1995). Eye-hand coordination: cooperative and competitive systems? [Doctoral Thesis, Maastricht University]. Rijksuniversiteit Limburg. https://doi.org/10.26481/dis.19950324hb

Document status and date:

Published: 01/01/1995

DOI:

10.26481/dis.19950324hb

Document Version:

Publisher's PDF, also known as Version of record

\section{Please check the document version of this publication:}

- A submitted manuscript is the version of the article upon submission and before peer-review. There can be important differences between the submitted version and the official published version of record.

People interested in the research are advised to contact the author for the final version of the publication, or visit the DOI to the publisher's website.

- The final author version and the galley proof are versions of the publication after peer review.

- The final published version features the final layout of the paper including the volume, issue and page numbers.

Link to publication

\footnotetext{
General rights rights.

- You may freely distribute the URL identifying the publication in the public portal. please follow below link for the End User Agreement:

www.umlib.nl/taverne-license

Take down policy

If you believe that this document breaches copyright please contact us at:

repository@maastrichtuniversity.nl

providing details and we will investigate your claim.
}

Copyright and moral rights for the publications made accessible in the public portal are retained by the authors and/or other copyright owners and it is a condition of accessing publications that users recognise and abide by the legal requirements associated with these

- Users may download and print one copy of any publication from the public portal for the purpose of private study or research.

- You may not further distribute the material or use it for any profit-making activity or commercial gain

If the publication is distributed under the terms of Article $25 \mathrm{fa}$ of the Dutch Copyright Act, indicated by the "Taverne" license above, 
Eye-hand coordination: Cooperative and competitive systems? 
CIP-GEGEVENS KONINKLIJKE BIBLIOTHEEK, DEN HAAG

Bekkering, Harold

Eye-hand coordination: Cooperative and competitive systems? / Harold Bekkering ; [ill. P.C.M. Langenhuizen].

- [S.1. : s.n.]. - 111 .

Thesis Rijksuniversiteit Limburg, te Maastricht. - With ref.

- With summary in Dutch.

ISBN 90-9008106-2

NUGI 711

Subject headings: eye-hand coordination / motor control. 
EYE-HAND COORDINATION: COOPERATIVE AND COMPETITIVE SYSTEMS?

\section{PROEFSCHRIFT}

ter verkrijging van de graad van doctor aan de Rijksuniversiteit Limburg te Mastricht, op gezag van de Rector Magnificus, Prof. mr. M.J. Cohen, volgens het besluit van het College van Dekanen, in het openbaar te verdedigen op vrijdag, 24 maart 1995 orn 14.00 uur

door

Harold Bekkering

Geboren te Oldenzaal op 19 Oktober 1965 
Promotores:

co-promotor:

beoordelingscommissie:
Prof. dr. A. Huson

Prof. dr. H.T.A. Whiting (University of York, UK)

Dr. J.J. Adam

Prof. dr. M.A. van den Hout (voorzitter)

Prof. dr. R.A. Abrams (Washington University, St. Louis, USA)

Prof. dr. C.J. Erkelens, (Universiteit Utrecht)

Dr. H. Merkelbach

Dr. J. Reulen

Prof. dr. A.J.W.M. Thomassen (Katholieke Universiteit Nijmegen)

Paranimfen: Frank van Poelwijk

Dennis Breuker

Het onderzoek uitgevoerd in het laboratorium van Prof. dr. R.A. A.brams aan de Washington University, St. Louis, USA, werd mede mogelijk gemaakt door het Stimuleringsfonds voor internationalisering (SIR 12-1466) plus een korte reisbeurs beide verstrekt door het NWG, en een persoonilijke subsidie ontvangen van de stichting "De Drie Lichten".

De uitgave van dit proefschrift werd ondersteund door SKALAR medical b.v. 
Aan Ellie,

liefste vriend,

geliefde en muze 



\section{Voorwoord}

Het schrijven van een voorwoord is een zeer aangename zaak; het betekent namelijk dat het overige werk gebeurd is. De goedkeuring over het proefschrift is verkregen en de afspraak met de drukker is gemaakt. Het is ook bij uitstek het moment om terug te blikken op het (A.I.O.-) leven van de afgelopen 4 jaar.

In het begin was het wel even wennen bij de vakgroep Bewegingswetenschappen na een plezierig en wetenschappelijk gezien zeer verwende tijd doorgebrachi te hebben bij het toenmalige Instituut voor ZintuigFysiologie (TNO). Geschikte apparatuur voor het meten van oogbewegingen diende nog aangeschaft te worden en de $\mathrm{x}$-y tafel - nodig voor het meten van de handbewegingen - moest voor revisie naar Amerika terug. Ondertussen werd er verder gesleuteld aan de opstelling. Iwan de Jong en Harry Wandler toonden zich onmisbaar bij het ontwikkelen van de software. Huub Jussen, Gerard Simons en Jan Aerts dachten mee met de ontwikkeling van de uiteindelijke opstelling en verzorgden daarnaast ook de uitvoering. Herman Kingma was in deze eerste fase op alle gebieden van groot belang, en bood mij ook de mogelijkheid om alvast enkele pilot-metingen te doen binnen zijn onderzoeksgroep op de afdeling $\mathrm{KNO}$ van het AZM.

Hoewel de glazen $\mathrm{x}$-y tafel de eerste keer in duizend stukjes terug kwam - en ik die dag ernstig overwoog om maatschappijleraar te worden - kon er na 1 1/2 jaar begonnen worden met de gewenste metingen. Misschien kwam het door de vele beschikbare denktijd, maar de eerste metingen leverden meteen zeer interessante gegevens op en boden bovendien vele mogelijkheden voor vervolgonderzoek. Dit onderzoek werd met de moed der wanhoop afgerond voor mijn vertrek naar Amerika, waarbij de enorme inzel van Ankie van der Aarssen ook buiten haar stagetijd om zeer waardevol is geweest.

My visit to the perceptual-motor laboratorium of Richard Abrams at the Washington University, St. Louis, USA, turned out to be the best thing that could happen to my thesis. Colloborating with Richard Abrams and Jay Pratt was extremely fruitful and I am sure that all my future scientific work will benefit of this experience. Heidi Korthase showed to be an excellent lab-assistent, who managed to run all the experiments in a short period of time. Moreover, the friendliness of Richard, Jay, Heidi, Heather, Mark, Allison, Deb, Pam and Niki made this period enjoyable far beyond the scientific borders!

Bij thuiskomst bleek het uur der waarheid aangebroken te zijn; het opschrijven van al dit experimentele werk. Gelukkig bleken Richard Abrams, Jay Pratt, Jos Adam en John Whiting daarbij ontzettend hulpvaardig. Hoogste tijd om over te gaan op het vermelden van diegene die het dichtst betrokken zijn geweest bij deze periode in mijn leven.

De beide promotores hebben ieder op hun manier een stempel gedrukt op dit proefschrift. Prof. John Whiting hield op zijn jaarlijkse bezoeken de grote lijn van het proefschrift goed in het oog en daarnaast op meer regelmatige basis door middel van vele "e-mailtjes". John, you are greatly acknowledged for your faith in me, particularly, for the fact that it was also there during the difficult starting phase of this project. Moreover, you always showed to be my "promotor" in a broad sense of this word. Prof. Toon Huson wil ik bedanken voor zijn steun en belangstelling voor het project door de jaren heen. Toon, ik heb altijd het gevoel gehad dat je deur openstond voor mijn problemen. Jos Adam had de ondankbare taak om mij op een meer dagelijkse manier te begeleiden. Hoewel onze samenwerking niet vlekkeloos is verlopen ben jij enorm belangrijk geweest bij de totstandkoming van de in dit proefschrift beschreven theorieën en meer algemeen in mijn vorming tot wetenschapper.

Verder wil ik graag de secretaresses Marion en Joke bedanken voor alle ondersteuning, waarbij met name Joke heeft zorggedragen voor de textuele lay-out van dit 
proefschrift. Ludo van Etten voorzag me van vele grafische adviezen. Gerard Houben, mijn kamergenoot, wil ik bedanken voor het aanhoren van mijn geklaag in slechtere wetenschappelijke tijden, zijn kritische kijk op enkele van mijn schrijfsels en vele zaken daarbuiten. Van de overige AIO's, wil ik met name Hennie, Matthijs, Jos en Rene bedanken voor de met hun komst toenemende gezelligheid binnen de vakgroep. Maarten en Paul wil ik bedanken voor het vanuit de vakgroep voorzien in ook nog enige sportieve daden gedurende deze jaren. De schaakclub VSM vormde voor mij echter de grootste bron van ontspanning; Gerrit, "Love", ik zal onze kwartiertjes missen in Munchen. De beide paranimfen zijn met zorg uitgekozen; Frank, een vriend die menig groeistuip met mij deelde en Dennis "Baby-Love" die voor veel plezier - en dikke oogjes - heeft gezorgd tijdens deze Maastrichtse jaren.

Mijn vader, moeder en broers bedank ik voor het meegeven van zoveel goeds uit het ouderlijk nest. Ellie, aan jou is dit proefschrift opgedragen. 


\section{Contents}

General Introduction $\ldots \ldots \ldots \ldots \ldots \ldots \ldots \ldots \ldots \ldots \ldots \ldots \ldots \ldots \ldots$

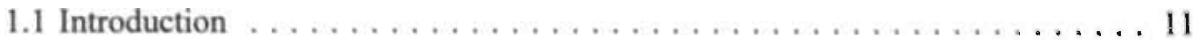

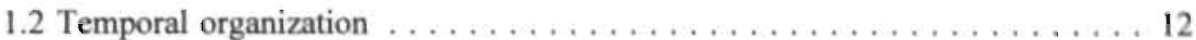

1.2.1 Temporal order . . . . . . . . . . . . . . . . . 12

1.2.2 Correlation between latencies . . . . . . . . . . . . . . 13

1.2.3 Dual-task methodology . . . . . . . . . . . . . . . . . 13

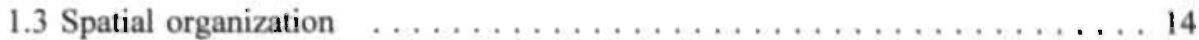

1.3.1 Retinal information ........................ 14

1.3.2 Extra-retinal information of the eyes . . . . . . . . . . . 15

1.3.3 Proprioceptive information about the hand $\ldots \ldots \ldots \ldots \ldots \ldots$

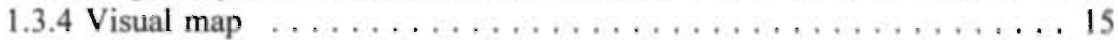

\section{EXPERIMENTS:}

2 RT latencies of eye and hand movements in single- and dual-task conditions . . . 21

3 Interference between saccadic eye and goal-directed hand movements $\ldots \ldots \ldots 31$

4 The gap effect for eye and hand movements $\ldots \ldots \ldots \ldots \ldots \ldots \ldots \ldots$ 7

5 The gap effect for spatially oriented responses $\ldots \ldots \ldots \ldots \ldots \ldots \ldots \ldots 6$

6 Transfer of saccadic adaptation to the manual motor system . . . . . . . . . . 69

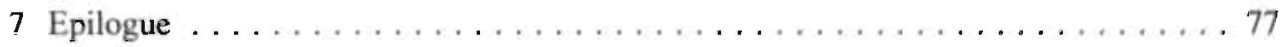

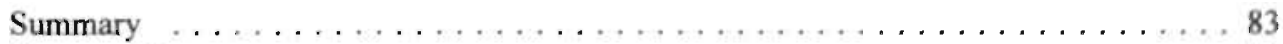

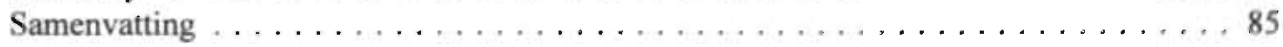

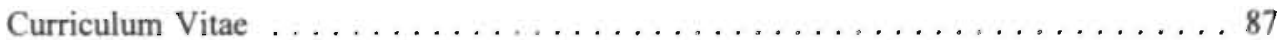




\section{1 \\ General Introduction}

\subsection{Introduction}

In order to interact effectively in the everyday world, man depends heavily on the close coupling between perceptual information and motoric action - the most important receptor for providing information about objects in the outside world being the eye. Typically, saccades rapid voluntary eye movements - will bring a new area of interest to the fovea, the central area of the retina where visual acuity is high. In order to produce aimed hand movements to a visual target, it is necessary to accurately map visual-spatial information about the target onto an appropriate set of commands for the muscles required to reach for, or point to, the object of interest. Although humans are very accurate in their goal-directed behaviour, the mechanisms underlying looking and pointing are quite complex and much remains to be learned about them.

Strikingly, most of our knowledge about the control of the eye and hand motor systems is based on research in which these motor systems have been studied separately. In order to produce eye movements it has been proposed that separate decisions need to be made about when eye movements are to be initiated and to where the eyes have to be directed (Becker \& Jurgens, 1979; Findlay, 1992). Becker and Jurgens (1979), for example, using a double-step paradigm confirmed this standpoint by demonstrating that latencies of correstion saccades were much shorter relative to (typical) saccadic latencies i.e., the when decisions were influenced independently of the where decisions.

Similar behaviour has also been observed for hand movement responses to double target step stimuli (e.g., Barett \& Glencross, 1988a, 1998b). This, together with a number of other similarities between limb and eye movements (e.g., Abrams, Meyer, \& Kornblum, 1989), suggests the possibility that separate decisions about when and where may also be made in the context of aimed hand movements.

Eye and hand responses have been found to show a large variability in the onset of the movements. The wide range of eye and hand latencies--even on different trials within one specific situation - might suggest that the "events in the human nervous system that immediately precede and allow for the execution of voluntary movements" (Rosenbaum, 1980, p. 444), contain a random element. Carpenter (1988) postulates a deliberate degree of variability in the operation of the central processes involved in eye movements, serving to prevent responses from becoming too stereotyped. Such a strategy could be related to the process of deciding whether there is, in fact, a target present and, if so, whether it is worth looking at, (Carpenter, 1988), a strategy which might be generalized to the manual motor system in the context of whether the stimulus is worth pointing at.

The end position of eye and hand movements in visual targeting are also very variable. 
While saccades can sometimes be accurate (Kapoula \& Robinson, 1986), they usually undershoot their goal slightly and sometimes overshoot it (Becker, 1972). The corrections made after an undershoot or overshoot range from being completed fairly quickly (dynamic overshoot and undershoot), to several hundred milliseconds (glissadic overshoot and undershoot), to even the generation of a secondary saccade. The manual system almost always contains distinct submovements, in which the first part - rather similar to saccadic eye movements - is mostly ballistic and serves to propel the limb most of the distance between the starting position and the target (e.g., Abrams, Meyer \& Kornblum, 1989). If the primary limb movement does not land in the target region, then a corrective, secondary, sub-movement may also be produced mainly on the basis of visual feedback provided by the eye (e.g., Abrams \& Pratt, 1993).

\subsection{Temporal organization}

At least three kinds of experimental method have been employed to investigate the temporal organization of eye and hand movements in the context of pointing to a visually presented target.

\subsubsection{Temporal order}

Results of studies addressed to the question whether eye and hand respond in a fixed order, typically show that the eyes start moving toward the target before the hand (e.g., Abrams et al., 1990, Biguer et al., 1982, Prablanc et al., 1986), and, because eye movements are quite brief, the eyes usually arrive at the target before the hand starts to move (Abrams et al., 1990). This serial movement order characterized as 'eye-first, hand-second', has led some researchers to infer that a limb can only be guided accurately after the eyes have reached the target (Paillard, 1982; Prablanc et al., 1986).

However, there are several reasons why eye latencies might have been shorter than hand latencies in these studies, which have nothing to do with the provision of high acuity, foveal information to guide the hand to the desired end position. For example, most studies have been carried out with abrupt visual stimulus onsets in a completely dark room. Todd and Van Gelder (1979) argue, that in such conditions saccadic eye movements may be automatically triggered probably because it is important to inspect areas of the visual field in which new information has just appeared. Another reason is that the complexity of the unknown, forthcoming, response demands a different amount of preparation time for eye and hand movements, i.e. preparation time to construct an eye movement (e.g., specifying the desired spatial and temporal properties of the forthcoming response) may be independent of accuracy demands, while construction of hand movements may depend, heavily, on the complexity of the forthcoming response (e.g., Christina et al., 1982; Fitts and Peterson, 1964; Fischman, 1984; Klapp, 1975; Quinn et al., 1980; Sideaway, 1991; Sideaway et al., 1988). In addition, the eye-first, hand-second phenomenon observed in previous studies may be attributable to the differing dynamical properties of eye and hand. "The dynamics of the manual system is determined mainly by its mass, whereas the dynamics of the ocular system can be described by a visco-elastic spring and a relatively small mass." Koken, 1993, p. 1). As a consequence, delays associated with muscle contraction for hand movements exceed those for eye movements (Biguer et al., 1982). 
A closely related, and perhaps more principal question regarding eye-hand coordination is whether eye and hand responses are initiated by one common command signal or whether the ocular and manual motor systems utilize different command signals to initiate their output. Typically, a correlational approach has been used to address this question.

\subsubsection{Correlation between latencies}

Correlations between eye and hand latencies have been used to answer the question whether eye and hand responses are initiated by one common or by different command signals. High correlations have been interpreted as evidence that eye and hand responses are initiated by a common command signal, while low correlations have been interpreted as evidence for independent signals.

Unfortunately, experiments using the correlational method have yielded inconsistent results. For example, Herman et al., (1981) reported high correlations $(r>0.6)$ and these were also found in one of the conditions of the experiments by Frens \& Erkelens (1991) and Fischer \& Rogal (1986). More modest correlations $(0.4<\mathrm{r}<0.6)$ have been reported by Gielen et al., (1984), Prablanc et al., (1979) and in another condition of the experiments by Fischer \& Rogal (1986). Low correlations $(r<0.4)$ were found by Biguer et al., (1982) and in another condition of the Frens \& Erkelens study (1991).

Modest correlations, however, can easily be attributed to a shared perceptual processing component without an additional shared output signal to the motor sysiems (Gielen et al., 1984). Higher correlation values, on the other hand, are more difficult to explain without the notion of a common command signal to the two motor systems. There are, however, some serious methodological objections to the Herman et al., (1981) study. Importantly, Herman et al., (1981) correlated paired values of all 5 subjects in one analysis, a method which is known to give rise to spurious correlation coefficients, i.e. five individual low correlations, can result in one overall high correlation coefficient. Another reason why Herman et al., (1981) may have found high correlation is suggested by Jeannerod (1988) who noted, that the subjects in the Herman et al., study received a training session which might have stabilized their RT latencies. Nevertheless, it is not quite clear why stabilized RT latencies of eye and hand responses should benefit the degree of covariation between eye and hand.

Overall, it seems that most studies fail to report high correlation coefficients. Whether the correlations are poor or modest seems to be related to the stimulus condition. For instance, Frens \& Erkeleñs (1991) found eye and hand movements to be generated independently, i.e. a low correlation coefficient when visual information is available and generated in a more related way when no visual information is available.

An alternative methodological approach to the issue of whether the eye and hand motor systems are driven by independent mechanisms is the so-called dual-task methodology.

\subsubsection{Dual-lask methodology}

In order to investigate dual-task interference in generating eye and hand movements, researchers have employed three conditions: In the two, single-task, conditions subjects have to make either eye or hand movements to a visual target, while in the dual-task condition both hand and eye are required to move to the visual target. 
The logic behind dual-task methodology in the context of temporal coupling of eye and hand is as follows: If eye and hand movements are executed simultaneously without an increase in RT latencies in the dual-task relative to the single-task condition, a strong argument is provided in favour of the assumption that both responses are mediated by independent processes. In the case that the RT latencies in the dual-task condition differ from those in the single-task condition, support is provided for the notion that the production of movements by eye and hand motor systems are interrelated in the production of their output.

Studies addressed to the question of dual-task performances of eye and hand movements have shown inconsistent results. Eye and hand latencies were found to be independent in studies by Fischer \& Rogal (1986) and Brown et al., (1994), while other studies found increased eye latencies in the dual-task condition compared to single-task performance (e.g., Mather \& Fisk, 1985; Warabi et al., 1986). No one, as yet, however, would appear to have tried to determine the underlying reasons for this inconsistency.

\subsection{Spatial organization}

Usually, humans reach the goal of eye and/or hand movements quite accurately. Apparently, the actor has an accurate "representation" of the location of his/her body and the objects in his/her environment. There are a number of potential sources of spatial information which would enable the generation of accurate, saccadic eye and aimed hand movements.

\subsubsection{Retinal information}

When a target appears in the peripheral field, retinal information about the target is provided by the patterns of light stimulation on the retina. For instance, information about the location and the movement of the object in the environment, about limb position and about the status of the ongoing movement. In particular, the relative positions of the target and the limb are important to the making of an accurate limb movement (Prablanc et al., 1986). Without all these different kinds of information, movement performance quickly deteriorates (e.g., Carlton, 1981: Keel \& Posner, 1968; Meyer et al., 1988a; Vince, 1948; Woodworth, 1899). Most models of initiation of the saccadic system assume that the oculomotor system attempts to minimize retinal error of the location of the image of the target on the retina relative to the fovea (Mays \& Sparks, 1980; Young \& Stark, 1963; Robinson, 1973). Moreover, the saccade is thought to be ballistic. In addition, most researchers suppose that preparation of a saccadic eye movement involves the specification of the direction and the distance through which it is required to move (e.g., Becker \& Jurgens, 1979; Hou \& Fender, 1979; Megaw \& Armstrong, 1973, Abrams \& Jonides, 1988; Abrams et al., 1989). More controversy seems to exist about preparation parameters for the hand in order to reach the goal. Complementary to the saccadic eye models, some researchers assume that people produce limb movements by specifying the direction and amount of force that the muscle must apply over time to the moving limb (e.g., Meyer et al., 1982; 1988; Schmidt et al., 1979).

However, other models consider retinal information about the location of the goal in space to provide all the information an actor needs to specify the desired state of a limb. The limb movement itself does not require explicit planning. Traditionally, these location-related 
models, regard the limb as a mass supported by opposing springs, i.e. the agonist and antagonist muscles (e.g. Feldman, 1986; Polit \& Bizzi, 1979; Sakitt, 1980). The limb is at rest when the forces discharged by an opposing set of muscles are exactly equal. Specification of a new desired end location demands a new equilibrium point for the limb, and a movement will be generated any time the limb is not at equilibrium (see also Abrams, Van Dillen \& Stemmons, 1994).

\subsubsection{Extra-retinal information of the eyes}

Extra-retinal (eye-position) information might also play a role in aimed limb movements. According to Helmholtz (18../1963) eye position information is needed to accurately localize objects, since retinal image position and object location with respect to the head are not fixed, but change as a result of eye movement. One possible non-retinal source of information might be the putative efference copies of motor commands to the extraocular muscles (e.g., Sperry, 1950). Another source of eye position information might be the orbital receptors: "If one is asked to estimate the length of a line, one's first reaction is to scan the line fixating each end in turn, as if to measure it in terms of the amount of ocular rotation required to traverse it." (McLaughlin et al., 1968, p. 45). Which of the two, or whether both sources provide information about eye position, is still a matter of debate (see also Bock, 1986; Carpenter, 1988). However, there is some evidence to suggest that subjects can guide a limb accurately to a spatial location based purely on extraretinal information aboul eye position (e.g., Hansen \& Skavenski, 1977; 1985; Prablanc et al., 1979). Nevertheless, much has to be proven before this assumption can be generalized (e.g., Abrams et al., 1990). One particular problem with determining the attribution of extra-retinal information independently of retinal information is that having the eyes at the target also enhances the retinal information about the target, i.e. the target can be viewed in central instead of peripheral vision (e.g., Pailiard, 1982).

\subsubsection{Proprioceptive information about the hand}

In addition to retinal information, humans have available proprioceptive information about the position and movements of the hand. Sittig and colleagues (1985a; 1985b; 1987) showed that a distinction has to be made between the control of position information and slow movement control of the limb on the one hand and the control of fast movements on the other. Joint receptors located in the capsules are supposed to provide information about joint position (and slow limb movements), while the muscle spindles, located in parallel with the extrafusal fibres are supposed to provide velocity information by means of changes in muscle length.

\subsubsection{Visual map}

In order to produce accurate goal-directed movements effectors need to have an unitary perception of the location of the body and the objects surrounding it, and this, so-called internal representation has, typically, to be updated by every change in the effector's posture or as objects change position in the surroundings. Apparently, the spatial information from the different sensory sources outlined above, is well matched. Several models have been proposed 
to explain how the body and the outside world are represented. Researchers have addressed questions about whether humans have an allocentric or egocentric representation (e.g., Blouin et al., 1993; Paillard, 1991)? Is space represented relative to the head or body (e.g., Bard et al., 1990; Soechting and Flanders, 1989)? Another, often questioned issue is whether eye and arm positions are represented in retinocentrally and jointcentrally coordinates, respectively, or in space coordinates (e.g., Hogan, 1988; Mays and Sparks, 1980; Soechting and Ross, 1984). The main concern of this thesis, however, is not with the nature of the representations per se, but instead the focus is on whether the manual motor and oculomotor systems are interrelated in terms of the mechanisms used to control the movements. Specifically, our inquiry is limited to the question whether the manual and oculomotor systems utilize two independent spatial sources of information to produce movements, or whether they are controlled from a common source. 


\section{References}

Abrams, R.A., Dillen, L. van, \& Stemmons, V. (in press). In C. Umilta, \& M. Moskovitch (Eds.) Attention and Performance $X V$.

Abrams, R.A., \& Jonides, J. (1988) Programming saccadic eye movements. Journal of Experimental Psychology: Human Perception and Performance, 14, 428-443.

Abrams, R.A, Meyer, D.E.M., Kornblum, S. (1989). Speed and accuracy of saccadic eye movements: Characteristics of impulse-variability in the oculomotor system. Journal of Experimental Psychology: Human Perception and Performance, 15, 529-543.

Abrams, R.A., Meyer, D.E.M., Kornblum, S. (1990). Eye-hand coordination: Oculomotor control in rapid aimed limb movements. Journal of Experimental Psychology: Human Perception and Performance, 16, 248-267.

Abrams R.A., \& Pratt J. (1993). Rapid aimed limb movements: Differential effects of practice on component submovements. Journal of Motor Behavior, 25, 288-298.

Bard, C., Fleury, M., Paillard, J. (1990). Different patterns in aiming and accuracy for head-movers and non-head movers. Journal of Human Movement Studies, 18, 37-48.

Barrett, N.C., \& Glencross, D.J. (1988a). The double step analysis of rapid manual aiming movements. Quarterly Journal of Experimental Psychology, 40, 229-322.

Barrett, N.C., \& Glencross, D.J. (1988b). The amplitude transition function and the manual and oculomotor control systems. Psychological Bulletin, 104, 363-372.

Becker, W. (1972). The control of eye movements in the saccadic system. Bibl Ophthal, 82, 233-243.

Becker, W., \& Jurgens, R. (1979). An analysis of the saccadic system by means of double step stimuli. Vision Research, 19, 471-476.

Biguer, B., Jeannerod, M., \& Prablanc, C. (1982). The coordination of eye, head and arm movements during reaching at a single visual target. Experimental Brain Research, 46, 301-304.

Blouin, J., Bard, C., Teasdale, N., Paillard, J., Fleury, M., Forget, R., \& Lamarre, Y. (1993). Reference system for coding spatial information in normal subjects and a deafferent patient. Experimental Brain Research ${ }_{4} 93$. 324-331.

Bock, O. (1986). Contribution of retinal versus extraretinal signals towards visual localization in goal-directed movements. Experimental Brain Research, 64, 476-482.

Brown, S.H., Kessler, K.R., Hefter, H., Cooke, J.D., \& Freund, H.J. (1993). Role of the cerebellum in visuomotor coordination: I. Delayed eye and arm initiation in patients with mild cerebellar ataxia. Experimental Brain Research, 94, 478-488.

Carlton, L.G. (1981). Processing visual feedback information for movement control. Journal of Experimental Psychology: Human Perception and Performance, 7, 1019-1030.

Carpenter, R.H.S. (1988). Movements of the eyes. Pion, London.

Christina, R.W., Fischman, M.G., Vercruyssen, M.J.P., \& Anson, J.G. (1982). Simple reaction time as a function of response complexity: Memory drum theory revisted. Journal of Motor Behavior, 14, 301-321.

Feldman, A. (1986). Once more on the equilibrum-point hypothesis (Lamda model) for motor control. Journal of motor behavior, 18, 17-54.

Findlay, J. (1992), Programming stimulus-elicited saccadic eye movements. In. K. Rayner (Ed.), Eye movements and visual cognition: Scene perception and reading (pp. 8-30). New York, Springer-Verlag.

Fischer, B., \& Rogal, L. (1986). Eye-hand coordination in man: A reaction time study. Biologicai Cybernetics, 55, 253-261.

Fischman, M.G. (198.4). Programming time as a function of number of movement parts and changes in movement direction. Journal of Motor Behavior. 16. 405-423.

Frens, M.A., \& Erkelens, C.J. (1991). Coordination of hand movements and saccades: Evidence for a common and a separate pathway. Experimental Brain Research, 85, 682-690.

Gielen, C.C.A.M., Heuvel van den P.J.M., \& Gisbergen van J.A.M. (1984). Coordination of fast eye and arm movements in a tracking task. Experimental Brain Research, 56, 154-161.

Hansen, R.M., \& Skavenski, A.A. (1985). Accuracy of spatial localizations near the time of saccadic eye movements. Vision Research, 25, 1077-1082. 
Helmholtz, H. von. (1867). Handbuch der Physiologischen Optik. Ist edition (Voss, Hamburg). 3rd edition translated by J.P.C. Southall for the optical society of America (1924).

Herman R., Herman R., \& Maulicci R. (1981). Visually triggered eye-arm movements in man. Experimental Brain Research, 42, 145-148.

Hogan, N. (1988). Planning and execution of multijoint movements. Canadian Journal of Physiology \& Pharmacology, 66, 508-517.

Hou, R.L., \& Fender, D.H. (1979). Processing of direction and magnitude by the saccadic eye-movement system. Vision Research, 19, 1421-1426.

Jeannerod, M. (1988). The neural and behavioural organization of goal-directed movements. Clarendon Press, Oxford.

Kapoula, Z.A., \& Robinson, D.A. (1986). Saccadic undershoot is not inevitable: saccades can beaccurate. Vision Research, 26, 735-743.

Keele, S.W., \& Posner, M.I. (1968). Processing of visual feedback in rapid movements. Journal of Experimental Psychology, 77, 155-158.

Koken, P.W. (1993). Human eye and hand movements in tracking tasks. (1993). Thesis University of Utrecht.

Mays, L.E., \& Sparks, D.L. (1980). Saccades are spatially, not retinotopically coded. Science, 208, 1163-1164.

Mather J.A., \& Fisk, J.D. (1985). Orienting to targets by looking and pointing: Parallels and interactions in ocular and manual performance. Quarterly Journal of Experimental Psychology, 37, 315-338.

McLaughlin, S., Kelly, M., Anderson, R., and Wentz, T, 1968. Localization of a peripheral target during parametric adaptation of saccadic eye movements. Perception \& Psychophysics, 4, 45-48.

Megaw, E.D., \& Armstrong. W. (1973). Individual and simultaneous tracking of a step input by the horizontal saccadic eye movement and manual control systems. Journal of Experimental Psychology, 100, 18-28.

Meyer, D.E., Abrams, R.A., Komblum, S., Wrigth, C.E., \& Smith, J.E.K. (1988). Optimality in human motor performance: Ideal control of rapid aimed hand movements. Psychoiogical Review, 95, 340-370.

Meyer, D.E., Smith, J.E.K., \& Wrigth, C.E. (1982). Models for the speed and accuracy of aimed movements. Psychological Review, 89, 449-482.

Paillard, J. (1982) The contribution of peripheral and central vision to visually guided reaching. In Ingle D, Goodale M, Mansfield R (Eds.), Analysis of visual behaviour (pp 367-385). MIT Press, Cambridge.

Polit, A., \& Bizzi, E. (1979). Characteristics of motor programs underlying arm movements in monkeys. Journal of Neurophysiology, 42, 183-194.

Prablanc, C., Echallier, J.F., Komilis, E., \& Jeannerod, M. (1979). Optimal response of eye and hand motor systems in pointing at a visual target: 1. Spatio-temporal characteristics of eye and hand movements and their relationship when varying the amount of visual information. Biological Cybernetics, 35, 113-124.

Prablanc, C., Pelisson, D., Goodale, M.A. (1986). Visual control of reaching movements without vision of the limb: I. Role of retinal feedback of target position in guiding the hand. Experimental Brain Research, 62, 293302 .

Robinson. D.A. (1973). Models of the saccadic eye movement control systern. Kybemetik, 14, 71-83.

Rosenbaum D.A. (1980). The movement precuing technique; Assumptions, applications, and extensions. In: R.A. Magill (ed.) Memory and control of action. Amsterdam, North-Holland, pp. 231-274.

Schmidt, R.A., Zelaznik, H., Hawkins, B., Frank, J.S., \& Quinn, J.T., Jr. (1979), Motor-output variability: A theory for the accuracy of rapid movements acts. Psychological Review, 86, 415-451.

Sideaway, B. (1991). Motor programming as a function of constraints on movement initiation. Journal of Motor Behavior, 23. 120-130.

Sittig, A.C., Denier van der Gon, J.J., Gielen, C.C.A.M., \& Wijk, A.J.M. van. (1985). The attainment of target position duping step-tracking moveemnts despite a shift of initial position. Experimenral Brain Research, 60. 407-410.

Sittig, A.C. Denier van der Gon, J.J., Gielen, C.C.A.M. (1987). The contribution of afferent information on position and velocity to the control of slow and fast human forearm movements. Experimental Brain Research, 67, 33-40.

Soechting, J.F., \& Flanders, M. (1989). Sensorimotor representation for pointing to targets in three-dimensional space. Journal of Neurophysiology, 62, 582-594.

Soechting, J.F., \& Ross, B. (1984). Psychophysical determination of coordinate representation of human arm 
orientation. Neuroscience, 13, 595-604.

Sperry, R.W. (1950). Neural basis of of the spontaneous optokinetic response produced by visual inversion. Journal of Comparative Physiology and Psychology, 43, 482-489.

Vince, M.A. (1948). Corrective movements in a pursuit task. Quarterly Journal of Experimental Psychology, 1. 85-103.

Warabi, T., Noda, H., Kato, T. (1986). Effect of aging on sensorimotor functions of eye and hand movements. Experimental Neurology, 92, 686-697.

Woodworth, R.S. (1899). The accuracy of voluntary movement. Psychological Review, 3.

Young, L.R., Stark, J. (1963). Variable feedback experiments testing a sampled data model for eye tracking movements. IEEE Trans Hum Factors Electron, 4, 38-51. 


\section{Reaction time latencies of eye and hand movements in single- and dual-task conditions*}

\section{Summary}

The goal of this study was to investigate whether ocular and hand motor systems operate independently or whether they share processes. Using dual-task methodology, reaction time (RT) latencies of saccadic eye and hand motor responses were measured. In Experiment 1 , the hand and eye motor systems produced rapid, aimed pointing movements to a visual target, which could occur either to the left or right of a central fixation point. Results showed that RT latencies of the eye response were slower in the dual-task condition than in the single-task condition whereas the RT latencies of the hand response were virtually the same in both conditions. This interference effect indicated that the ocular and manual motor systems are not operating independently when initiating saccadic eye and goaldirected hand movements. Experiment 2 employed the same experimental paradigm as Experiment 1, except for one important modification: Instead of a goal-directed hand movement to the target stimulus, subjects had to make a button-press response with either the index or middle finger of the right hand dependent upon whether the stimulus occurred to the right or left of the control fixation point. The aim of Experiment 2 was to investigate the issue whether the observed interference effect in Experiment I was specific or non-specific (e.g., overhead costs due to coordinating any two responses). The finding that saccadic eye movements and button-press responses in the dual-task condition could be initiated without delay relative to the single-task conditions, supports the specific. interference interpretation.

\section{Introduction}

This paper focuses on temporal coupling between eye and hand movements in the context of pointing to a visual target. In the last decade two relevant questions regarding this issue have been examined: First, whether initiation of eye and hand responses occur in a fixed or variable order (e.g., Abrams et al., 1990; Biguer et al., 1982, Prablanc et al., 1986) and, second, whether eye and hand responses are initiated by one common command signal or by different command signals (e.g., Fischer \& Rogal 1986; Frens \& Erkelens, 1991; Herman et al., 1981; Prablanc et al., 1979).

\footnotetext{
- Published in Experimental Brain Research, 97, 1994, 471-476. Co-authors: J.J. Adam, H. Kingma, A. Huson and H.T.A. Whiting.
} 
Results of studies addressed to the first question are straightforward: Almost always the eyes start moving toward the target before the hand, and because eye movement durations are quite brief, the eyes usually arrive at the target before the hand starts to move (Abrams et al., 1990).

Answers to the second question, however, are not quite so straightforward. Typically. a correlational approach has been used in order to determine the degree of co-variation between reaction time (RT) of eye and hand movements; high correlations being interpreted as evidence that eye and hand responses are initiated by a common command signal, low correlations as evidence for independent command signals.

Experiments using the correlational method have yielded inconsistent results - widely differing correlations having been reported both within and between studies. For example, low correlations ( $r<0.4$ ) were reported by Biguer et al., 1982, and by Frens \& Erkelens 1991; modest correlations $(0.4<\mathrm{r}<0.6)$ by Gielen et al., 1984, Prablanc et al., 1979, and by Fischer \& Rogal 1986; high correlations ( $\mathrm{r}>0.6$ ) were found by Herman et al., 1981 and also in some of the conditions of experiments by Frens \& Erkelens 1991 and by Fischer \& Rogal 1986. Because the majority of the studies fail to report high correlations and because low and modest correlations can easily be attributed to a shared perceptual processing component (Gielen et al., 1984), strong evidence in support of the common command hypothesis is lacking.

Failure to obtain evidence for the common command hypothesis, however, does not automatically constitute evidence in favour of the independent commands hypothesis. Theoretically it is still possible that eye and hand motor systems do work together, but that the degree of cooperation is insufficient to realize strong correlations. To investigate the issue whether eye and hand motor systems operate independently or whether they share processes, dual-rask methodology' was employed in this study. In the single-task condition subjects had to make either eye or hand movements to a visual target while in the dual-task condition both hand and eye were required to move to the visual target.

The logic behind dual-task methodology is as follows. When eye and hand movements are executed simultaneously without. an increase in RT latencies in the dual-task condition relative to the single-task. conditions, a strong argument is found in favour of the assumption that both responses are mediated by independent processes. In the case that the RT latencies in the dual-task condition differ from those in the single-task conditions, support is found for the notion that movements produced by eye and hand motor systems share processes.

\section{Experiment 1}

Experiment l was designed to study RT latencies of eye and hand movements in single and dual-task conditions. The experimental task required subjects to move (either with the eyes alone, hand alone, or concurrently with eyes and hand) as quickly as possible to a large target stimulus appearing either to the left or right of a central fixation point. The choice of a large

\footnotetext{
'The term dual-task methodology in this: paper refers to the procedure of studying RT latencies of eye and hand movemenus in single and dual-task conditions. Note that the dual-task condition is used in most studies on eye-hand coordination but the single-task condition is not.
} 
target size was motivated by the wish to impose low accuracy constraints i.e., to demand only a ballistic hand response without the need for visually guided error corrections.

\section{Method}

\section{Subjects}

Twelve right-hand preferent undergraduate ( 3 male and 9 female) students, (mean age 22 years), participated as non-paid, voluntary, subjects. 9 subjects had normal vision. The three subjects with glasses were not allowed to wear them during the experiment. As all these subjects had an acuity of at least 18/20 dioptre the nature of any impairment they experienced was inconsequential for performing visual tasks at short distances as was the case in the present task. All were naive as to the purpose of the experiment.

\section{Design}

Each subject served in three conditions on a single day, with each condition lasting 10 minutes with a break of 5 minutes between conditions. In the Eye-Only condition, only the eyes moved to the stimulus; in the Hand-Only condition only the hand moved to the stimulus while the eyes remained fixated on the fixation point; in the Eye-and-Hand condition both eyes and hand moved to the stimulus. Order of conditions was balanced between subjects.

\section{Apparatus}

The experiment was carried out in a normally illuminated room which contained many visual cues. The subject stood behind a horizontally placed transparent $X-Y$ tablet (Scriptel RDT, 105$80 \mathrm{~cm}$ ). Underneath the $\mathrm{X}-\mathrm{Y}$ tablet a tv-monitor (Phillips, $54-40 \mathrm{~cm}$ ) was mounted which was controlled by an AT-MSDOS computer. On the monitor a fixation sign was presented in line with the subject's eyes at a distance of about $28 \mathrm{~cm}$. The fixation stimulus was a 'filled dot' of $2 \mathrm{deg}$ in angle; the stimulus was a 'filled rectangle' presented at a distance of 15.9-24.9 deg of visual angle. Positions of subject's eyes were monitored with an IRIS system. This system records eye position by reflection of iris-sclera boundaries by means of infrared light; the output of the IRIS system is low-pass filtered ( $200 \mathrm{~Hz},-3 \mathrm{~dB})$; for details see Reulen et al., 1988. The analog output from the IRIS was digitized at a rate of $200 \mathrm{~Hz}$. Calibration was performed at the beginning of each session. The head was fixated by a frame which was connected to the IRIS $35 \mathrm{~cm}$ above the middle of the X-Y tablet, so that the eyes were directly above and looking down at the control fixation dot.

The subjects were requested to move a stylus with their right hand over the surface of the X-Y tablet which recorded X-Y coordinates with an accuracy of $0.1 \mathrm{~mm}$ at a rate of 172 $\mathrm{Hz}$.

\section{Procedure}

10 practice trials preceded 20 experimental trials. At the beginning of each trial the subjects were requested to place the stylus on the fixation point. After $2 \mathrm{~s}$ the target stimulus appeared 
randomly either to the left or to the right of the fixation point. Subjects were instructed to make saccadic eye movements and/or ballistic hand movements towards the target. They were also instructed to minimize both RT and movement time (MT) of eye and/or hand.

\section{Eye-movement analysis}

The position data generated by the IRIS system were off-line analyzed by means of the software programm NYSTAGLINER (Toennies, Würzburg) to identify the occurrence of saccades. The beginning of a saccade was defined when the signal exceeded the value of the Root Mean Square (RMS) of the previous $120 \mathrm{~ms}$ with a factor 3 within a subsequent window of $20 \mathrm{~ms}$. A trial was excluded from the analysis when another saccade or eye blinking appeared within $100 \mathrm{~ms}$ before or after this point of detection. The same criteria were used to check fixation of the eyes in the Hand-Only condition. Because all subjects showed almost perfect binocular coordination between horizontal saccades (correlation values for each subject $>$.99), only data concerning the right eye are presented ${ }^{2}$.

\section{Hand-movement analysis}

Detection of changes in hand movements (RTs) were calculated by a computer algorithm which inciuded four criteria: The first three samples had to differ at least one unit in $\mathrm{x}$-direction (one unit corresponds to $0.1 \mathrm{~mm}$ ) from each other, the fourth more than one, the fifth more than two and the sixth sample had to differ more than three units from its preceding $\mathrm{x}$-coordinate.

\section{Correlation analysis}

Within subject Pearson correlation coefficients were calculated on a trial by trial basis between eye and hand RTs in the dual-task condition. In addition, a between subject Pearson correlation was calculated using the subjects' mean RTs of eye and hand in the dual-task condition.

\section{Results}

The results of one subject were excluded because eye blinks occurred in more than $25 \%$ of the trials which required eye movements. For the remaining 11 subjects, $10.0 \%$ of trials which required saccadic eye movements in the Eye-Only condition and $11.8 \%$ in the Eye-and-Hand condition were excluded (see Method section: eye movement analysis).

Table 1 shows mean RT and standard deviation of eye and hand movements in single and dual-task conditions.

\footnotetext{
${ }^{2}$ Ali trials were visually inspected; in about $10 \%$ of the trials of both Eye-Only and Eye-and-Hand' conditions the automatic detection of a saccade was manually corrected. These manual corrections were invoked when significant eye-drifts occurred.
} 
Table 1. Mean RT latencies (ms) and standard deviations (ms) for eye and hand aiming responses in single-and dualtask conditions (Experiment 1).

\begin{tabular}{|l|l|l|}
\hline & EYE & HAND \\
\hline SINGLE-TASK & $222 \pm 35$ & $234 \pm 41$ \\
\hline DUAL-TASK & $261 \pm 41$ & $238 \pm 42$ \\
\hline
\end{tabular}

An ANOVA yielded a significant main effect for task condition (single $v s$ dual), $F(1,10)=12.7$, $p<.01$, indicating longer reaction times in the dual-task than in the single-task condition (249 and $229 \mathrm{~ms}$, respectively). The main effect of type of movement (eye $v s$ hand) was not significant, $\mathrm{F}(1,10)=0.1, p>2$. Importantly, a significant interaction effect was found between type of movement and task condition, $\mathrm{F}(1,10)=19.3, p<.01$. A paired, two-tailed, t-test $\mathrm{T}(10)$ $=4.52, p<.002$ indicated that RT of the eyes was significantly longer $(39 \mathrm{~ms})$ in the dual-task condition than in the single-task condition.

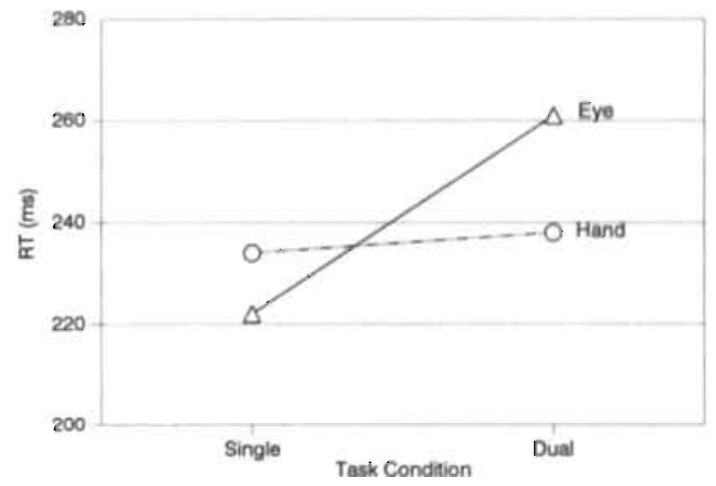

Figure 1. Mean RT latencies (ms) of eye and hand aiming responses in both single and dual-task conditions (Experiment I). Fig. I shows that saccadic eye RT latencies are longer in the dual-task condition than in the single-task condition.

RT latencies of the hand were virtually identical in single and dual-task conditions $(\mathrm{T}(10)=.23$, $p>.8$ ). The RT latencies of the eyes and the hand were not significantly different from each other in the dual-task condition $\left(\mathrm{T}(10)=1.45, p>.15^{3}\right.$.

\footnotetext{
${ }^{3}$ The mean difference between RT latencies of eye and hand in dual-task condition was $23 \mathrm{~ms}$. However, the large variation in eye and hand RTs (sd=54) makes this difference non-significant.
} 
None of the individual (within-subjects) correlations between eye and hand RTs was significant, all $p$ 's being larger than .05 . The between-subjects correlation was $0.14, p>.05$

\section{Discussion}

The main finding of Experiment 1 was that RT latencies of the eyes were consistently and significantly longer in the dual-task condition than in the single-task condition while those of the hand did not differ significantly. In addition, no significant correlations were found. Nonsignificant or low correlations do not support the common command hypothesis but, as stated in the introduction low correlations do not constitute strong evidence for the notion that the eye and hand motor systems operate independently. In fact, the interference effect for the eye response in the dual-task condition indicates that the ocular and manual motor systems do not operate independently; but rather, that at some stage, processes are shared.

The question to which this finding gives rise is whether or not the observed interference effect is specific or non-specific i.e., the consequence of being required to produce any two responses or the sharing of specific processes in the context of pointing to a target.

One way to discriminate between these two interpretations is to manipulate the nature of the manual response. This is done in Experiment 2.

\section{Experiment 2}

The same paradigm as for Experiment 1 was used except for one imporiant modification: Instead of a goal-directed hand movernent to the target stimulus, subjects had to make a buttonpress response with either the index or middle finger of the right hand. Specifically, the left target stimulus required a button-press response with the index finger and the right target stimulus a button-press response with the middle finger. The same saccadic eye movement was required as in Experiment 1.

The purpose of this manipulation is straightforward: If Experiment 2 shows the same interference effect as found in Experiment 1, support is provided for non-specific interference. On the other hand, if the interference effect disappears, support is found for a specific interference effect ciused by a sharing of processes associated with the control of coordinated aimed eye and hand movements.

\section{Method}

\section{Subjects}

Twelve right-hand preferent undergraduate ( 5 male and 7 female) students (mean age 23 years) participated as non-paid, voluntary, subjects. All had normal vision, and all were naive as to the purpose of the experiment. None of them had taken part in the previous experiment. 


\section{Procedure}

Instead of making a goal-directed hand movement, subjects were requested to press one of two buttons on a response box with either the index finger when the stimulus was presented to the left of the fixation sign or with the middle finger when the stimulus wasi to the right. The subjects were required to keep the two fingers on the buttons during the experiment.

\section{Design: see Experiment 1.}

Eye-movement analysis: see Experiment 1.

Finger-movement analysis

A connection was made between the response box and the AT-MSDOS computer by means of the joystick port. This port scanned both button states (high or low value) at a rate of $1000 \mathrm{~Hz}$. The values were analyzed off-line. A trial was excluded when no response occured within a period of $750 \mathrm{~ms}$, or when at subject pressed the wrong button.

\section{Results}

$3.1 \%$ of trials requiring saccadic eye movements in both the Eye-Only and the Eye-and-Finger condition were excluded. $0.7 \%$ of trials requiring finger responses in the Finger-Only and $1.7 \%$ of trials in the Eye-and-Finger condition were excluded.

Figure 2 shows the mean RT latencies of eye and finger responses in single and dualtask conditions. A main effect was found for type of movement, indicating that the RT latencies of the eyes $(217 \mathrm{~ms})$ were significantly shorter than the RT latencies of the finger $(316 \mathrm{~ms})$, $\mathrm{F}(1,11)=44.5, p<.001$. No main effect was found for task condition, $\mathrm{F}(1,11)=3.2, p>0.05$.

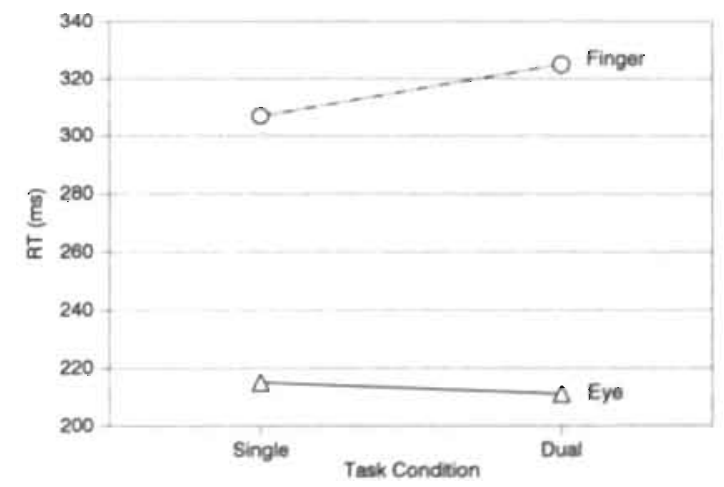

Figure 2. Mean RT latencies (ms) of eye and button-press responses in both single and dual-task conditions (Experiment 2). Figure, 2 shows that saccadic eye RT latencies and buttor-press RT latencies are similar in single and dual-task conditions. 
The most important result of Experiment 2 was the absence of a significant interaction effect between type of movement (eye vs finger) and task condition (single vs dual), $\mathrm{F}(1,11)=0.6, p>.2$.

\section{Discussion}

The purpose of Experiment 2 was to investigate whether the interference effect between the eye and hand response observed in Experiment 1 was due to specific or non-specific interference. The finding that saccadic eye movements and button-press responses in the dual-task condition could be initiated without delay relative to the single-task conditions, supports the specific interference interpretation.

\section{General discussion}

The experiments here reported produced three major findings.

\section{Experiment 1:}

i. the absence of a temporal order effect - There were no significant differences between the RT latencies of eye and hand in the dual-task condition.

ii. an interference effect - An increase in saccadic eye RT latencies in the dual-task relative to the single-task condition.

Experiment 2:

iii. a task-specific effect - No increase in either the saccadic or button-press RT latencies in the dual-task relative to the single-task condition.

\section{Temporal order}

The common finding in the literature of dual-task conditions involving sye-hand coordination movements to a target is that the eye starts to move in the direction of the target before the hand (see Introduction for references). The discrepant finding reported in Experiment 1 seems to indicate that this order of eye and hand responses may be due to the specific task requirements. Traditionally, experiments on eye-hand coordination have involved a relatively small target - for example, a light emitting diode - which, because of the need for precise foveal information to guide the hand accurately to the desired end position may invoke serial order operation of eye and hand motor systems. In Experiment i, such stringent demands were not imposed on subjects. Speed and not accuracy of both eye and hand movements was stressed and, to this end, large targets were used and only two possible target positions employed. The absence of a temporal order effect in the present dual-task condition calls into question the generality of the eye-first, hand-second phenomenon. In their first experiment, Abrams et al., (1990) found that subjects spontaneously executed a saccade toward the target of their rapid aimed limb movements but that only three of four subjects tested began to move their eyes first. 
(1990) found that subjects spontaneously executed a saccade toward the target of their rapid aimed limb movements but that only three of four subjects tested began to move their eyes first. They phrased this finding as 'The saccade is closely time locked to the initiation of the limb movement, although its order of occurrence does not seem crucial: Limb movements (e.g., wrist rotation) are equivalent whether they lead or follow an eye movement' (pp 254). The actual movement order therefore may depend on the behavioral task involved, as for instance the amount of uncertainty about the spatial location of the target.

The finding that saccadic eye movement latencies were slightly larger in the experiments reported here than those to be found in the literature can probably be accounted for by the fact that most researchers extinguished the fixation light at the moment the target appeared. This extinction has been shown to provide an extra cue that reduces saccadic latency (e.g. Reulen 1984). Other investigations within a so called overlap paradigm showed indeed saccadic RT latencies of the same order (e.g., Fischer \& Rogal, 1986).

\section{Task-specific interference effect}

The fact that no increase in RT latencies was observed either for the eye or for the hand in Experiment 2, where finger-press responses were required, suggests that the observed interference effect of Experiment 1 is restricted to situations in which both hand and eye are functionally involved in moving to a target position.

In a related study done with eye and hand movements within a dual-task paradigm, Fischer and Rogal (1986) found saccadic eye latencies to be independent of whether or not they were combined with hand movements. However, in contrast to the present study they used small targets ( $1 \mathrm{deg} * 1 \mathrm{deg}$ ). This task constraint may induce subjects to first move the eyes to the target position and subsequently the hand; in other words, small targets may demand serial operation of ocular and manual motor systems, while large targets may demand parallel operation. Frens \& Erkelens (1991) also concluded that depending on the task constraints, coordination of hand and eye movements involves parallel and independent control, or the sharing of specific processes.

Both the finding that eye and hand RTs were not significantly different from each other in the dual-task condition and the finding that none of the subjects showed a significant correlation between eye and hand RTs indicate that the augmentation of saccadic eye RTs in the dual-task relative to the single-task condition is not due to an eye-is-waiting-the-hand phenomenon. Further research is being carried out in our laboratory to investigate the nature and locus of the delay that ensues when saccadic eye responses are combined with goal-directed hand movements.

Because saccades have stereotyped velocity profiles and because they show quick orienting behaviour under all kind of circumstances, the saccadic system has often been considered to be an automatically reacting open-loop system (e.g., Young \& Stark, 1963; Posner et al., 1978, Prablanc \& Pelisson, 1990). Clearly, the results of Experiment 1 in which a significant increase in saccadic RT latency was observed in the dual-task condition calls the generality of this conceptualization into question. 


\section{References}

Abrams, R.A., Meyer, D.E.M., \& Komblum, S. (1990). Eye-hand coordination: Oculomotor control in rapid aimed limb movements, Journal of Experimental Psychology. Human Perception and Performance, 16(2), 248-267.

Allport, D.A., Antonis, B., \& Reynolds, P. (1972), On the division of attention. A disproof of the single channel hypothesis. Quarterly Journal of Experimental Psychology, 24, 225-235.

Biguer, B., Jeannerod, M., \& Prablanc, C. (1982). The coordination of eye, head and arm movements during reaching at a single visual target. Experimental Brain Research, 46, 301-304.

Carpenter, R.H.S. (1988). Movements of the eyes. Pion, London.

Findlay, J.M. (1982). Global visual processing for saccadic eye movements. Vision Research, 22, 1033-1045.

Fischer, B., \& Rogal, L. (1986). Eye-hand coordination in man: A reaction time study. Biological Cybernetics, 55, 253-261.

Folk, C.L., Remington, R.W., Johnston, J.C. (1992). Involuntary covert orienting is contingent on control settings. Journal of Experimental Psychology. Human Perception and Performance, 18(4), 1030-1044.

Frens, M.A., \& Erkelens, C.J. (1991). Coordination of hand movements and saccades: evidence for a common and a separate pathway. Experimental Brain Research, 85, 682-690.

Gielen, C.C.A.M., Heuvel, van den P.J.M., \& Gisbergen, van J.A.M. (1984). Coordination of fast eye and arm movements in a tracking task. Experimental Brain Research, 56, 154-161.

Herman, R. Herman, R., Maulicci, R. ((1981). Visually triggered eye-arm movements in man. Experimental Brain Research, 12, 145-148.

Kahnemann, D. (1973). Attention and effort. Englewood Cliffs NY: Prentice-Hall.

Keele, S.W. (1981). Behavioral analysis of movement. In V Brooks (Ed). Handbook of physiology: The nervous system. Vol 2 Motor control (pp 1391-1414). Baltimore MD: American physiological society.

Navon, D . \& Miller, J. (1987). Role of outcome conflict in dual-task interference. Journal of Experimental Psychology. Human Perception and Performance, 13(3), 435-448.

Paillard, J. (1982). The contribution of peripheral and central vision to visually guided reaching. In Ingle D, Goodale M. Mansfield R. (Eds.) Analysis of visual behaviour (pp 367-385). Cambridge: MIT Press.

Pashler, H. (1990), Do response modality effects support multiprocessor models of divided attention? Journal of Experimental Psychology, Human Perception and Performance, 16, 826-842.

Pashler, H., \& Johnston, J. (1989). Chronometric evidence for central postponement in temporally overlapping tasks. Quarterly Journal of Experimental Psychology, 41 A, 19-45.

Posner, M.I., Nissen, M.J., \& Ogden, W.C. (1978). Attended and unattended processing modes: The role of set for spatial location. In Pick H, Saltzman E (Eds). Modes of perceiving and processing information (pp 137157). Hillsdale:Erlbaium.

Prablane, C. Echallier, J.F., Komilis, E., Jeannerod, M. (1979). Optimal response of eye and hand motor systerns in pointing at a visual target: 1. Spatio-temporal characteristics of eye and hand movements and their relationship when varying the amount of visual information. Biological Cybernetics, 35, 113-124.

Prablanc, C., Pelisson, D. (1990). Gaze saccade orienting and hand pointing are locked to their goal by quick internal loops. In M. Jeannerod (Ed). Attention and Performance XIII.

Prablanc, C., Pelisson, D., \& Goodale, M.A. (1986). Visual control of reaching movements without vision of the limb: 1. Role of retinal feedback of target position in guiding the hand. Experimental Brain Research, 62, 293302.

Reulen, J.P.H. (1984), Latency of visually evoked saccadic eye movennents. I. Saccadic latency and the facilitation model. Biological Cybernetics, 50, 251-262.

Reulen, J.P.H., Marcus, J.I., Koops, D., Vries, de F.R., Tiesinga, G., Boshuizen, K. \& Bos, J.T. (1988). The precise recording of eye movement: The Iris technique, part I. Medical Biological Engineering Computarion, 26, 2026.

Young, L.R., Stark, J. (1963). Variable feedback experiments testing a sampled data model for eye tracking movements. IEEE Trans Human Factors Electronic 4, 38-51. 


\section{3}

\section{Interference between saccadic eye and goal-directed hand movements}

\section{Summary}

The aim of the present study was to investigate the nature of the interference effect - i.e., longer eye latencies - when the eye is accompanied by a goal-directed hand movement than when it moves alone. Latencies of eye and hand responses were measured in response to small and large visual target stimuli, while employing dual-task methodology. Experiment 1 and 2 were designed to investigate whether the interference effect is related to a specific temporal bottleneck, i.e. the eye and hand motor systems share limited available processes at a specific point in time. The findings of robust interference effects independent of the temporal organization of eye and hand contradicted this notion. In Experiment 3 subjects knew in advance where the target would appear. In this situation the interference effect disappeared, implicating mechanisms concerned with response-selection of the movements as the source of the interference effect. Experiment 4 showed that the interference effect disappeared in the context of highly salient stimuli, suggesting that highly salient stimuli engage the "reflexive" Superior Colliculus pathway, thereby bypassing response selection mechanisms. The neurophysiological implications of the findings are discussed.

\section{Introduction}

Humans frequently experience great difficulty when performing two distinct motor tasks at the same time and initiation of one or both tasks is often delayed as compared to single-task performance (e.g., Fagot \& Pashler, 1992; Sternberg, 1969; Pashler, 1984; 1989; 1990; Pashler \& Johnston, 1989). Research on dual-task performance seeks to understand the fundamental causes of this interference and, thus, provide insight into the functional organization of the brain (Pashler et al., 1993). Studies addressed to the question of dual-task performances of eye and hand movements have, typically, shown that the eye movement was delayed in the dual-task condition compared to the single-task condition (e.g., Bekkering et al., 1994; Mather \& Fisk 1985; Warabi et al., 1986). This observed interference effect suggests that at some level processes associated with the control of coordinated aimed eye and hand movements are shared.

A closely related question regarding the temporal coupling between eye and hand movements in the context of pointing to a visual target, is whether they occur in a fixed or variable order (e.g. Abrams 1990; Biguer et al., 1982; Prablanc et al., 1986). Almost always

\footnotetext{
"Submitted in modified version to Experimental Brain Research. Co-authors: J.J. Adam, A. van den Aarssen, H. Kingma and H.T.A. Whiting
} 
the eyes have been found to start moving before the hand, and, because eye movements are quite brief, the eyes usually arrive at the target before the hand starts to move (Abrams et al., 1990). However, Bekkering et al., (1994), in an experiment designed to investigate the temporal coupling between eye and hand movements while imposing low accuracy constraints, demonstrated the absence of such a temporal order effect. The discrepant finding that eye and hand responses occurred concurrently was interpreted in terms of specific task demands. Traditionally, experiments have involved relatively small target stimuli, such as a light emitting diode (LED). The employed large, visually presented target stimuli in the Bekkering et al., (1994) study, however, presumably took away the need for precise foveal information to guide the hand accurately to the desired end position.

The present study was designed to investigate the nature of the interference effect, i.e. longer eye latencies when the eye is accompanied by a goal-directed hand movement than when the eye moves alone. In the first experiment, an attempt was made to invoke different temporal order relations of eye and hand responses, i.e. a shift from a simultaneous operation order for responses to large target stimuli to a more serial eye-first, hand-second operation order for responses to small target stimuli. If the interference effect is related to a specific temporal bottleneck, i.e. the eye and hand motor systems share limited available processes at a specific point in time, less interference might be expected when eye and hand responses are executed more serially in response to small target stimuli.

\section{Experiment 1}

\section{Materials and methods}

\section{Subjects}

Six right-hand preferent undergraduate and graduate students, (all male, mean age 2.6 years), participated as non-paid, voluntary, subjects. All had normal vision and all were naive as to the purpose of the experiment.

\section{Design}

Each subject served in two sessions on a single day. Both sessions consisted of three conditions with each condition lasting about 10 minutes and a break of at least 60 minutes between sessions. One session included responses to small visual target stimuli and the other session responses to large visual target stimuli. Order of sessions was balanced between subjects. In the eye-only condition, only the eyes moved to the stimulus; in the hand-only condition only the hand moved to the stimulus position while the eyes remained fixated on the fixation point; in the eye-and-hand condition both eyes and hand moved to the stimulus position. Order of conditions was balanced between subjects and was kept constant between sessions. 


\section{Apparatus}

The experiment was carried out in a normally illuminated room which contained many visual cues. The subject stood behind a horizontally placed transparent X-Y tablet (Scriptel RDT, $105-80 \mathrm{~cm}$ ). Underneath the $\mathrm{X}-\mathrm{Y}$ tablet a tv-monitor (Philips, $54-40 \mathrm{~cm}$ ) was mounted which was controlled by an AT-MSDOS computer. On the monitor, small and large target stimuli were presented in line with subject's eyes at a distance of about $30 \mathrm{~cm}$. Therefore, each degree of visual angle corresponded to a distance of $.52 \mathrm{~cm}$ on the monitor. The centre of the circular stimuli was presented at a distance of $15^{\circ}$ of visual angle to the left or right of fixation. The diameter of small stimuli was equivalent to $.5^{\circ}$, while the diameter of large stimuli was equivalent to about $8^{\circ}$ of visual angle. Positions of subject's eyes were monitored with an IRIS system. This system records eye position by reflection of iris-selera boundaries by means of infrared light (Reulen et al., 1988). The analog output from the IRIS was digitized at a rate of $200 \mathrm{~Hz}$. Calibration was performed at the beginning of each session. The head was fixed by a frame which was connected to the IRIS, $40 \mathrm{~cm}$ above the middle of the X-Y tablet, so that the eyes were directly above and looking down at the control fixation dot.

The subjects were requested to move a stylus with their right hand on the X-Y tablet which recorded X-Y coordinates with an accuracy of $0.1 \mathrm{~mm}$ at a rate of $172 \mathrm{~Hz}$.

\section{Procedure}

In each experimental condition 1 block of 8 practice trials preceded 3 blocks of 8 experimental trials. At the beginning of each trial, subjects were requested to place the stylus on the fixation point. After $2 \mathrm{~s}$, the target stimulus appeared randomly either to the left or to the right of the fixation dot. Subjects were required to move (eyes alone, hand alone, or eyes and hand concurrently) as quickly as possible to either a small or a large target stimulus. Subjects were instructed to move as quickly as possible to the target region, but to end within the target region. Subjects received no feedback regarding the behaviour of eyes or hand.

\section{Eye-movement analysis}

The analog output of the IRIS was stored on an MSDOS computer after a block of trials. These data points were analyzed off-line by means. of the software program NYSTAGLINER (Toennies, Würzburg). In order to identify the occurrence of saccades the signal was differentiated. The beginning of a saccade was defined to be at the first moment in time at which the velocity of the eye exceeded $10 \%$ and remained above that value for at least $10 \mathrm{~ms}$ while subsequently exceeding $35 \%$ s. The end of the saccade was defined to be at the first moment in time afterward at which the velocity of the eye fell below $10 \% \mathrm{~s}$ (algorithm is identical to that of Abrams et al., e.g., 1989; 1990). This algorithm results in values for saccades onset and terminations that are in excellent agreement with judgment based on visual inspections of the trajectories. Using this algorithm, it was possible to reliably detect the occurrence of saccades larger than about $.5^{\circ}$ of visual angle. The velocity algorithm was also used to check fixation of the eyes in the hand-only condition. Because all subjects showed almost perfect binocular coordination between horizontal saccades (correlation values for each subject $>.999$ ), only data concerning the right eye are presented. 


\section{Hand-movement analysis}

The digital output of an $x-y$ tablet was transferred to the IRIS-MSDOS computer by means of a DA-port. The resulting analog output was stored after a block of trials. The beginning of a hand movement was defined to be at the first moment at which the velocity of the hand exceeded $5 \% \mathrm{~s}$ and remained above that value for at least $10 \mathrm{~ms}$ while subsequently exceeding $25 \%$. The end of the hand movement was defined to be at the first moment in time afterward at which the velocity of the hand fell below $5 \% \mathrm{~s}$. Using this algorithm we were able to reliably detect the occurrence of hand movements larger than $.2^{\circ}$ of visual angle.

\section{Correlation analysis}

Within-subject Pearson correlation coefficients were calculated on a trial by trial basis between eye and hand RTs in the dual-task condition of the two sessions of all subjects.

\section{Results}

RTs. Saccadic eye RTs were substantially shorter than hand RTs, $[F(1,5)=11.8, p<.02]$. Also, a main effect was found for task-condition, $[\mathrm{F}(1,5)=8.03, \mathrm{p}<.04]$, indicating shorter $\mathrm{RT}$ latencies in the single-task condition than in the dual-task condition.

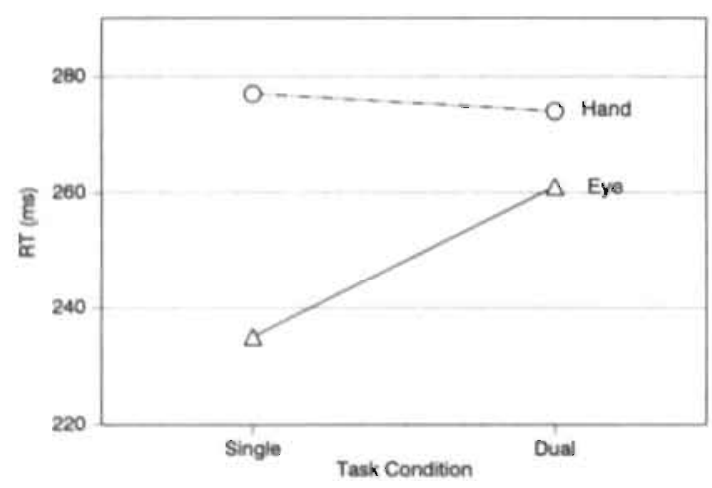

Figure 1. Mean RT latencies (ms) of eye and hand aiming responses in single- and dual-task conditions (Experiment i). Saccadic eye RT latencies are longer in the dual-task condition than in the single-task condition.

Additionally, subjects shawed shorter RT latencies to large target stimuli than to small target stimuli, $[F(1,5)=21.8, p<.01]$. 
Figure 1 demonstrates the interference effect, longer eye RT latencies in the dual-task condition than in the single-task condition, [i.e., type of movement and task-condition interacted; $F(1,5)$ $=12.18, p<.02]$. The absence of a 3-way interaction indicated that the interference effect was independent of target size, $[F(1,5)<1]$. Overall, latencies in single- and dual-task condition were 235 and $261 \mathrm{~ms}$ for eye responses, respectively, and 277 and $274 \mathrm{~ms}$ for hand responses. Figure 2 provides evidence for a shift in temporal organization: The lengthening of RT latencies to small target stimuli was more pronounced for hand movements $(47 \mathrm{~ms})$ than for eye movements $(30 \mathrm{~ms})$ [i.e., the effects of type of movement and size of target interacted; $F(1,5)$ $=30.3, p<.004]$.

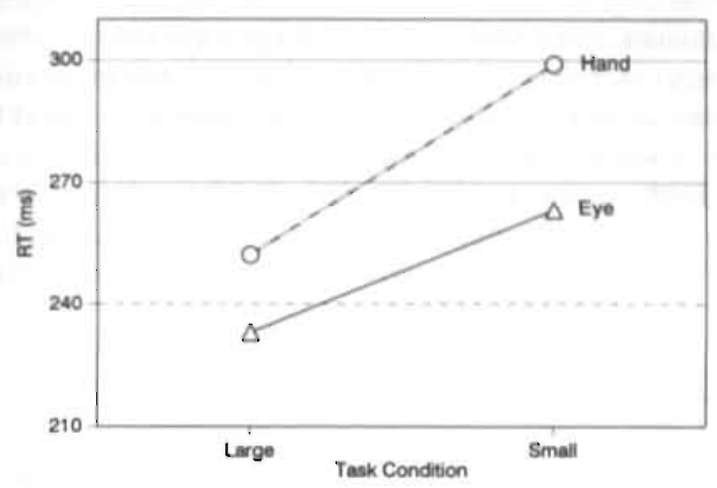

Figure 2. Mean RT latencies (ms) of eye and hand aiming responses to large and small target stimuli (Experiment 1). Hand latencies are more prolonged for responses to small stimuli compared to responses to large stimuli than eye latencies.

In fact, two-tailed, paired, t-tests demonstrated that RT latencies of eye and hand responses were significantly different for small targets $[T(5)=2.62, p<.05]$, but not for large targets $[T(5)<1]$.

Carrelations. Strong correlations between saccadic eye and hand RT latencies in the dual-task condition were found for each subject in response to small target stimuli $[p$ 's $<.001$ for ali 6 subjects, (mean correlation $=.77$, sd \pm 5$)]$ However, more modest correlations were found in response to large target stimuli, [mean correlation $=.58$, sd \pm 25 ].

\section{Discussion}

The first experiment showed robust interference effects, that is augmentation of saccadic eye latency in the dual-task condition relative to the single-task condition for eye movements to 
large target stimuli as well as for eye movements to small target stimuli. These findings are consistent with an interpretation that the interference effect is not due to a specific temporal bottleneck, i.e. related to the kind of temporal organization of eye and hand responses. However, it could be argued that Experiment 1 was only partially successful in manipulating the temporal operation order of eye and hand responses. That is, because only two target positions were used, accuracy demands were still rather low. Therefore, Experiment 2, sought to investigate further the temporal bottleneck hypothesis by increasing the number of target positions presented.

\section{Experiment 2}

The same paradigm as for Experiment 1 was used in order to provide a more critical test of the specific temporal bottleneck hypothesis of the interference effect. This was achieved by presenting the small target stimulus of Experiment 1 at 24 different positions rather than the original 2, i.e. directional accuracy demands were further increased. Hand latencies are known to increase substantially when accuracy demands increase (e.g., Christina et al., 1982; Sideaway, 1991; Sideaway et al., 1988), while eye latencies are rather independent of accuracy constraints (e.g., Carpenter, 1988). It might, therefore, be expected that eye and hand responses would be executed more serially - eye-first, hand second - in response to 24 small target stimuli than to 2 smali target stimuli.

\section{Materials and methods}

\section{Subjects}

Twelve right-hand preferent (under)graduate, ( 8 female and 4 male) students (mean age 24 years), participated as non-paid, voluntary, subjects. They were drawn from the same pool as those in Experiment 1, but none had served previously.

\section{Design}

Each subject served in one session on a single day, which consisted of three conditions with each condition lasting about 10 minutes and a break of at least 5 minutes between conditions. In the eye-only condition, only the eyes moved to the stimulus; in the hand-only condition only the hand moved to the stimulus position while the eyes remained fixated on the fixation point; in the eye-and-hand condition both eyes and hand moved to the stimulus position. Order of conditions was balanced between subjects.

\section{Apparatus}

The same small target size stimulus as used in Experiment 1 was presented at 24 different target positions. Eight possible target positions were equally spaced in the upper half of three imaginary circles, respectively, $4.8^{\circ}, 9.6^{\circ}$ and $13.4^{\circ}$ of visual angle away from the fixation dot, which depicted the centre of the hypothetical circles. So, all target positions, were presented in the upper half of subject's visual field. 


\section{Procedure}

Identical to Experiment 1, only now subjects were required to move (eyes alone, hand alone, or eyes and hand concurrently) as quickly as possible to only a small target stimulus.

Eye-movement, Hand-movement and Correlational analysis were identical to Experiment 1.

\section{Results}

RTs. Figure 3 shows mean RT latencies of eye and hand movements in single- and dual-task conditions. Saccadic eye RTs were significantly shorter than hand RTs $(232$ and $335 \mathrm{~ms}$, respectively, $[F(1,11)=133, p<.0001]$. No main effect was found for task-condition, $F(1,11)$ $<1$. Importantly, the movement by task type interaction was significant $[F,(1,11)=11, p<$ .008]. Paired, two-tailed, t-tests, revealed the interference effect, i.e. significant longer eye RT latencies in the dual-task condition than in the single-task condition, 241 and $224 \mathrm{~ms}$, respectively $[T(11)=2.37, p<04]$. RTs of the hand were significantly longer in the single-task condition than in the dual-task condition, 343 and $326 \mathrm{~ms}$, respectively $[T(11)=3.16, p<01]$.

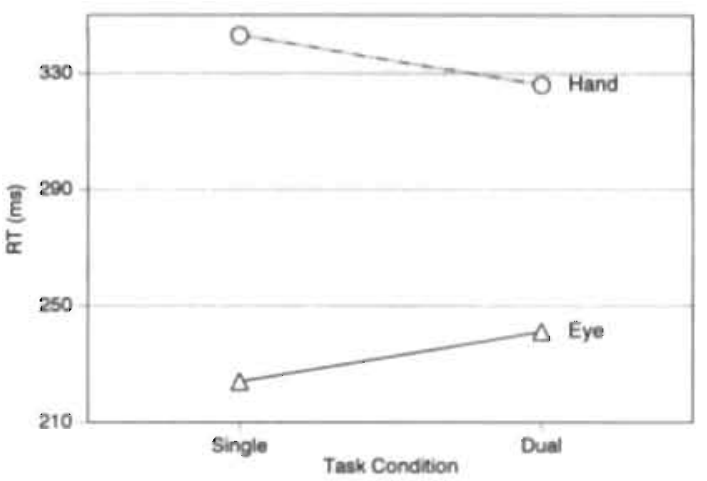

Figure 3. Mean RT latencies (ms) of eye and hand aiming responses in single- and dual-task conditions to 24 possible target positions (Experiment 2). Saccadic eye RT latencies are longer in the dual-task condition than in the single-task condition.

Correlations. Very variable correlations were found for subjects on a trial by trial basis between saccadic eye and hand RT latencies in the dual-task condition, but only being significant for 4 subjects $(\mathrm{p}<.01)$ and ranging between -.19 and .90 (mean $=.40$, sd \pm .36 ). 


\section{Discussion}

Increasing the number of possible target positions to 24 resulted in a larger temporal separation between eye and hand response onset than in Experiment 1, where only two target positions were employed (113 ms versus $27 \mathrm{~ms}$, respectively). Nevertheless, a robust interference effect materialized. This finding is not consistent with the interpretation that the interference effect is related to a specific temporal bottleneck, i.e. due to a sharing of limited available processes at a specific point in time.

In the dual-task literature, converging evidence has been provided for the idea that the most fundamental cause of interference is the selection of responses (see Pashler, 1992 for a review). Experiment 3 was designed to investigate the response-selection bottleneck hypothesis of the interference effect.

\section{Experiment 3}

Bekkering et al.'s (1994) dual-task paradigm was used again and the same large visual target stimulus was employed as in their Experiment 1. The response-selection bottleneck hypothesis was tested by providing subjects with advance information about where the target would appear. Presumably, this procedure allows advance selection of the required responses and consequently limits contribution of response-selection processes to the reaction time interval. Consistent with this logic is the observation that advance information about target position considerably reduces RT latencies of both eye (Abrams et al., 1988; Findlay, 1992) and hand responses (Adam, 1994; Rosenbaum, 1989). According to the response-selection bottleneck hypothesis, bypassing response-selection processes by providing advance information, should eliminate the interference effect.

An important procedural modification was introduced. That is, if subjects know both where and when the stimulus is going to appear, eye movements can be produced that are virtually in synchrony with the stimulus onset (e.g., Saslow, 1967). For this reason the stimulus appeared randomly in a time period between 1.5 and $2.5 \mathrm{~s}$ after presentation of the fixation stimulus.

\section{Materials and methods}

\section{Subjects}

Twelve right-hand preferent undergraduate ( 3 male and 9 female) students, (mean age 22 years), participated as non-paid, voluntary, subjects. All had normal vision, and all were naive as to the purpose of the experiment. They were drawn from the same pool as those in Experiment 1 and 2, but none had served previously.

Procedure, Design, Eye-movement and Hand-movement analysis were identical to Experiment 2. 
Apparatus

Identical to Experiment 1 and 2, only now, a filled rectangle between $11^{\circ}$ and $19^{\circ}$ to the right of the fixation dot - similar to the one used in the Bekkering et al.,'s paper (1994) - was presented in Experiment 3.

\section{Results}

Figure 4 shows mean RT of eye and hand movements in single and dual-task conditions. No main effects were found either for type of movement [eye versus hand, $F(1,11)<1$ ], or for task condition [single versus dual, $F(1,11)=2.2, p>.15$ ]. Importantly, no interaction effect was found between type of movement and task condition, $[F(1,11)=1.19, p>.25]$, indicating the absence of the interference effect.

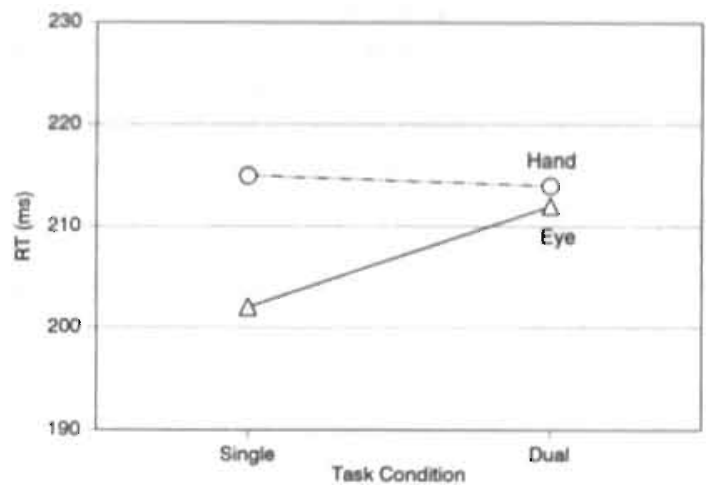

Figure 4. Mean RT' latencies (ms) of eye and hand aiming responses in single- and dual-task conditions when subjects have advance infomation about target position (Experiment 3). Saccadic eye RT latencies are not significant different in single- and dual-task conditions.

Correlations. Eight of the 12 subjects showed highly significant correlations between eye and hand RT latencies in the dual-task condition, $[p<.01$, (mean $=.57$, sd \pm .32$)]$.

\section{Discussion}

The fact that the interference effect disappeared when subjects knew in advance where the target would appear strongly implicates mechanisms concerned with response-selection as the source of the interference effect. This conclusion is consistent with a growing body of evidence demonstrating processes associated with response selection to be responsible for dual-task 
performance decrements (see also Pashler, 1992 for a review).

An interesting finding was that eye and hand RTs were not reliably different. A possible interpretation of this outcome is that when subjects know in advance where to point they are able to select the two responses as one unit, i.e., chunk their output and consequently produce similar RT latencies in single-task and dual-task conditions.

The goal of the last Experiment was to provide a further test of the response-selection bottleneck hypothesis of the interference effect.

\section{Experiment 4}

Several researchers have pointed out that saccades can be generated by two different neural pathways. One system originates in the Superior Colliculus (SC) and the other in the frontal eye fields (FEF) and associated frontal structures. The SC pathway is generally regarded as being critical in "reflexive" eye movements (e.g., Frens \& Erkelens, 1991; Pashler et al 1993; Wurtz \& Goldberg, 1972). In contrast, the FEF pathway seems to be critical for cognitively driven saccades which presumably require mechanisms concerned with response selection. In the present experiment, the response-selection bottleneck hypothesis was tested by employing highly salient stimuli which were designed to trigger saccades via the SC pathway. According to the response-selection bottleneck hypothesis, use of highly salient visual stimuli should make the interference effect disappear.

Saliency was manipulated by increasing the contrast between the stimulus and the background. This was accomplished by covering the digitizer with a black plate, while it was transparent in previous experiments.

\section{Materials and methods}

\section{Subjects}

Six right-hand preferent (under)graduate ( 4 male and 2 female) students, (mean age 25 years), participated as non-paid, voluntary, subjects. All had normal vision, and all were naive as to the purpose of the experiment. They were drawn from the same pool as those in Experiment 1,2 and 3, but none had served previously.

Procedure, Design, Eye-movement and Hand-movement analysis were identical to Experiment 1.

\section{Apparatus}

Identical to Experiment 1, only now, a black plastic plate covered the digitizer. An aperture of $30 * 25 \mathrm{~cm}$ was made in the middle of this plate. Depending on the size of the target in a session, this aperture was covered by a second plate containing either two small holes equal to the small stimuli of about $.5^{\circ}$, or two large hole, equal to the large stimuli of $8^{\circ}$. 


\section{Results and Discussion}

Saccadic eye RTs were substantially shorter than hand $\mathrm{RTs},[F(1,5)=11.8, p<.02]$. Additionally, subjects showed shorter RT latencies to large target stimuli than to small target stimuli, $[F(1,5)=17.2, p<.01]$. No main effect was found for type of task-condition, $F(1,5)$ $<1$, indicating similar RT latencies in single-task and dual-task conditions.

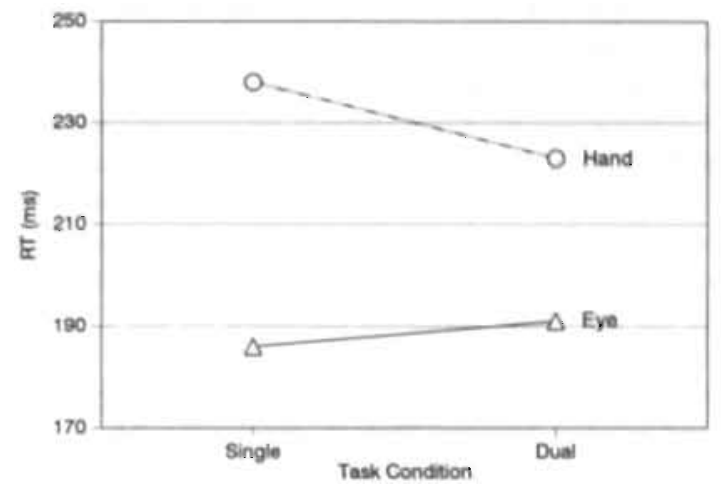

Figure 5. Mean RT latencies (ms) of eye and hand aiming responses in single- and dual-task conditions to salient stimuli (Experiment 4). Saccadic eye RT latencies are not significant different in single- and dual-task conditions.

of movement and task condition $[F(1,5)=12.18, p<.02]$. However, t-tests indicated that this interaction was not due to the interference effect for the eye response (there was no interference effect) but due to a facilitative effect for hand responses in the dual-task condition relative to the single-task condition. Whereas the last finding is hard to interpret, the absence of the interference effect is in accordance with the response-selection bottleneck hypothesis. That is, highly salient stimuli engage the "reflexive" SC pathway and thus preclude involvement of response selection mechanisms. The absence of a three-way interaction between type of movement, task condition and target size, $F(1,5)<1$, indicated that the observed effects were independent of target size.

Consistent with Experiment 2 it was found that the lengthening of RT latencies to small target stimuli was more pronounced for hand movements $(57 \mathrm{~ms})$ than for eye movements (17 ms) [i.e., the effects of type of movement and size of target interacted; $F(1,5)=18, p<.009$ ].

Correlations. Very strong correlations between saccadic eye and hand RT latencies in the dual-task condition were found for responses to small target stimuli, $[p$ 's $<.001$ for 5 out of 6 subjects, (mean correlation $=.74, \mathrm{sd} \pm 19)]$. However, more modest correlations were found for responses to large target stimuli, [mean correlation $=.59, \mathrm{sd} \pm 17$ ] 


\section{General Discussion}

\section{Temporal order}

Experiment 1 and 4 showed that size of the target is an important determinant of the temporal order of eye and hand responses: Small target. stimuli invoked the eye-first, hand-second operation order, whereas large target stimuli invoked concurrent initiation of eye and hand responses. The replication of the finding that eye and hand could be initiated concurrently when responding to a large target stimulus provides strong evidence for our notion that 'The actual movement order therefore may depend on the behavioural task involved...", (Bekkering et al., 1994, p. 475). Also this finding suggests that there is little reason to believe that information delivered by the eye after moving to and foveating the target is essential for programming ballistic, goal-directed limb movements. Rather, the spatial information used to program the eye movement might also be used to program the primary hand movement. Secondary hand submovements - correctional movements necessary to end within the target region - on the contrary, depend heavily on the visual feedback provided by the eye (e.g., Abrams \& Pratt, 1993).

Experiment 2 showed that target uncertainty is also an important determinant of the temporal order of eye and hand responses. That is, employing 24 target locations prolonged hand latencies more than eye latencies. Consequently, a large temporal gap between onset of eye and hand movement was observed.

\section{Interference effect}

Experiments 1 and 2 showed robust interference effects for eye movements when accompanied by a goal-directed hand movement independent of the temporal order operation of eye and hand. This outcome conflicts with the notion that the interference effect is related to the temporal organization of eye and hand responses, i.e., due to a specific temporal bottleneck of sharing limited available processes at a specific point in time.

Experiment 3 showed that the interference effect was absent when subjects knew in advance where the target would appear, indicating processes concerned with response selection as a possible source of the interference effect. Experiment 4 showed that "reflexive" generated saccades, i.e. triggered by highly salient stimuli do not produce the interference effect. This outcome is in accordance with the response-selection bottleneck hypothesis of the interference effect.

Neurophysiological interpretations. Two possible neurophysiological interpretations of the interference effect are possible. First, there is accumulating evidence indicating that two distinct pathways from the visual cortex to the oculomotor system are used for the generation of saccades, i.e., the SC pathway and the FEF pathway. Possibly, performing a second goaldirected task may tend to inhibit the use of the more "reflexive" SC pathway and elicit the more cognitive oriented FEF pathway. Consistent with this interpretation is Pashler's (1993) argument that bottleneck-dependent processes may "..just be the operations that are carried out by the FEF." (p.79). Only when the response-selection mechanisms can be preset (advance target position information, Experiment. 3) or by-passed (highly salient stimuli, Experiment. 4), saccades might be generated by the "reflexive" SC pathway, precluding the interference effect 
to materialize.

However, a second interpretation is provided by other researchers (e.g., Brooks, 1986; Miall et al., 1987, 1993; Stein, 1986). They argue that eye and hand responses have to be coordinated at higher control levels during reaching to a single visual target The cerebellum is a likely candidate for such a coordination control centre. Recently, Brown and colleagues (1993) examined the initiation of eye and arm movements in patients with mild cerebellar ataxia in a discrete step-tracking task. They found that when only the eyes were required to track a target, saccadic latencies were unaffected by cerebellar dysfunction. However, in the dual-task condition cerebellar patients showed increased saccadic latencies compared to control values. They maintained that the cerebellum may not be required for the generation of saccadic eye movements, but that it does play an important role in the initiation of concurrent eye and hand movement responses. It could be speculated that this coordination component, play a role in the occurrence of the interference effect.

\section{Degree of covariation}

Across experiments, correlations between eye and hand latencies varied dramatically and no consistent pattern could be identified. For instance, the finding in Experiment 1 of stronger correlations for small than for large target stimuli, could have indicated that higher accuracy demands on the responses might have lead to a tighter coupling between the two motor systems. However, the finding of more modest correlations in Experiment 2 where subjects had to respond to 24 target positions, clearly contradicted this hypothesis. This lack of consistency and aiso the high variability between subjects within the same experiment suggests that correlation values between eye and hand RT latencies may be non-informative. The processes in the human nervous system that immediately precede and allow for the execution of movement responses may contain a deliberate random element (Carpenter, 1988). Carpenter's motivation for postulating such a deliberate degree of variability in the operation of central processes of eye movements is that it prevents responses from becoming too stereotyped, a strategy which could be related to the process of deciding whether in fact there is a target, and if so, whether it is worth looking at (Carpenter, 1988). Thus, the widely differing correlations reported within and between many other studies (see also Bekkering et al., 1994), leaves some serious doubts about the usefulness of a correlational approach in the study of eye-hand coordination when pointing to a visual target. 


\section{References}

Abrams, R.A., \& Jonides, J. (1988), Programming saccadic eye movements. Journal of Experimental Psychology: Human Perception and Performance, 14, 428-443.

Abrams, R.A., Meyer, D.E.M., \& Kornblum, S. (1989), Speed and accuracy of saccadic eye movements: Characteristics of impulse-variability in the oculomotor system. Journal of Experimental Psychology: Human Perception and Performance, 15, 529-543.

Abrams, R.A., Meyer, D.E.M., \& Komblum, S. (1990). Eye-hand coordination: Oculomotor control in rapid aimed limb movements. Journal of Experimental Psychology: Human Perception and Performance, 16, 248-267.

Abrams, R.A., \& Pratt, J. (1993). Rapid aimed limb movements: Differential effects of practice on component submovements. Journal of Motor Behavior, 2, 288-298.

Adam, JJ. (1994). Manipulating the spatial arrangement of stimuli in a precuing task. Acta Psychologica, 85, 183202.

Bekkering, H., Adam, J.J., Kingma, H., Huson, A., \& Whiting, H.T.A. (1994). Reaction time latencies of eye and hand movements in single and dual-task conditions. Experimental Brain Research 97, 471-476.

Biguer, B., Jeannerod, M., \& Prablanc, C. (1982). The coordination of eye, head and arm movements during reaching at a single visual target. Experimental Brain Research, 46, 301-304.

Brooks, V.B. (1986). The neural basis of control. Oxford University Press, New York pp 256-289.

Brown, S.H., Kessler, K.R., Hefter, H., Cooke, J.D. \& Freund, H.J. (1993). Role of the cerebellum in visuomotor coordination: I. Delayed eye and arm initiation in patients with mild cerebellar ataxia. Experimental Brain Research, 94, 478-488.

Carpenter, R.H.S. (1988). Movements of the eyes. Pion London

Christina, R.W., Fischman, M.G., Vercruyssen, M.J.P. \& Anson, J.G. (1982). Simple reaction time as a function of response complexity: Memory drum theory revisted. Journal of Motorical Behavior, 14, 301-321.

Fagot, C., \& Pashler, H. (1992). Making two responses to a single object: Implications for the central attentional bottleneck. Journat of Experimental Psychology: Human Perception and Performance, 18, 1058-1079.

Findlay, J.M. (1992). Programming stimulus-elicited saccadic cye movements. In K Rayner (ed) Eye movements. and visual cognition: Scene perception and reading. New York: Springer Verlag pp 8.30.

Frens, M.A., Erkelens, C.J. (1991), Coordination of hand movements and saccades: Evidence for a common and a separate pathway. Experimental Brain Research, 84, 682-690.

Mather, J.A., \& Fisk, J.D. (1985). Orienting to targets by looking and pointing: Parallels and interactions in ocular and manual performance. Quarterly Journal of Experimental Psychology, 37A, 315-338.

Miall, R.C., Weir, D.J., \& Stein, J.F. (1987), Visuo-motor tracking during reversible inactivation of the cerebellum. Experimental Brain Research, 65, 455-464.

Miall, R.C., Weir, D.J., Wolpert, D.M., \& Stein, J.F. (1993). Is the cerebellum a Smith predictor? Journal of Motor Behavior, 25, 203-216.

Pashler, H. (1984). Processing stages in overlapping tasks: Evidence for a centrai bottleneck. Journal of Experimental Psychology: Human Perception and Performance, 10, 358-377.

Pashler, H. (1989). Dissociations and dependencies between speed and accuracy: Evidence for a two-component theory of divided attention in simple tasks. Cognitive Psychology, 21, 529-574.

Pashler. H. (1990). Do response modality effects support multiprocessor models of divided attention? Journal of Experimental Psychology: Human Perception and Performance, 16, 826-842.

Pashler, H. (1992). Dual-task interference and elementary mental mechanisms. In D Meyer, S Komblum (eds.) Attention and Performance XIV. Cambridge MA: MIT Press.

Pashler, H., \& Johnston, J.C. (1989). Chronometric evidence for central postponement in temporally overlapping tasks. Quarterly Journal of Experimental Psychology, 41A, 19-45.

Pashler, H., Hoffman, J., \& Carrier, M. (1993). Saccadic eye movements and dual-task interference. Quarterly Journal of Experimental Psychology, 46A, 51-82.

Prablanc, C., Pelisson, D., \& Goodale, M.A. (1986). Visual control of reaching movements without vision of the limb: 1. Role of retinal feedback of target position in guiding the hand. Experimental Brain Research, 62, 293302 . 
Reulen, J.P.H., Marcus, J.I., Koops, D., Vries, de F.R., Tiesinga, G., Boshuizen, K, \& Bos, J.T. (1988), The precise recording of eye movement: The Iris technique, part 1. Medical and Biological Engineering and Computing. 26, 20-26.

Rosenbaum, D.A. (1980). The movement precuing technique: Assumptions, applications, and extensions. In: R.A. Magill (ed.) Memory and control of action. Amsterdam: North-Holland, pp. 231-274

Saslow, M.G. (1967). Latency for saccadic eye movement. Journal of Optical Society of America, 57, 1030-1033.

Sideaway, B., Christina, R.W., \& Shea, J.B. (1988). A movement constraint interpretation of the response complexity effect and programming time. In A Colley \& J Beechs (eds) Cognition and action in skilled behaviour Amsterdam: North-Holland, pp 87-102.

Sideaway, B. (1991). Motor programming as a function of constraints on movement initiation. Journal of Motor Behaviour, 23, 120-130.

Stein, J.F. (1986). The role of the cerebellum in the visual guidance of movement. Nature, 323, 217-221.

Sternberg, S. (1969). The discovery of processing stages: Extensions of Donders' method. Acta Psychologica, 30, 276-315.

Warabi, T., Noda, H., \& Kato, T. (1986). Effect of aging on sensorimotor functions of eye and hand movements. Experimental Neurology, 92, 686-697.

Wurtz, R.H. \& Goldberg. M.E. (1972). Activity of superior colliculus in behaving monkey: III Cells discharging before eye movements. Journal of Neurophysiology, 35, 575-586. 


\section{4 \\ The gap effect for eye and hand movements}

\section{Summary}

A temporal gap between fixation point offset and stimulus onset results in shorter saccadic latencies than keeping the fixation stimulus on. Several researchers have explored the extent to which the gap also reduces latencies of other responses but have failed to find a gap effect isolated from general warning effects. Experiment 1, however, shows a robust gap effect for aimed hand movements, independent of whether the hand moved alone or was accompanied by a saccadic eye movernent. Experiment 2, replicates this aimed hand gap effect and also shows a small effect for choice manual keypress responses. Experiment 3, shows no gap effect for simple manual keypress responses. The results are consistent with an interpretation of the gap effect in terms of facilitation of spatial oriented responses.

\section{Introduction}

Coordination between the oculomotor and manual motor systems is essential for successful interaction with our daily environment. However, a great deal of our knowledge about the control of these motor systems is based on results of experiments in which these systems have been studied separately. There is, however, some evidence from studies that required concurrent eye and hand movements that the oculomotor and manual motor systems are interrelated during the production of goal-directed movements to a visual target (e.g., Abrams, Meyer \& Komblum, 1990; Bekkering, Adam, Kingma, Huson \& Whiting, 1994; Bekkering, Abrams, \& Pratt, under review; Nemire \&. Bridgeman, 1987). One useful approach to examine the relation between oculomotor and manual motor systems is to exarnine eye and hand movements, using a paradigm that has been successfully applied to one of the motor systems. The present study was designed to explore the "gap effect" - a temporal gap between the fixation point offset and stimulus onset (known to have a robust influence on the oculomotor system) on eye and hand responses.

The "gap effect"

A temporal gap between the offset of a fixation point and the onset of a target stimulus results

\footnotetext{
"Submitted to Perception \& Psychophysics. Co-authors: I. Pratt and R.A. Abrams.
} 
in shorter saccadic latencies than if the fixation point remains visible (e.g. Fischer \& Ramsperger; 1984; Reulen, 1984a, 1984b; Reuter-Lorenz, Hughes \& Fendrich, 1991; Saslow, 1967). The reduced latencies produced by the advance offset of fixation have been referred to as the "gap effect", and they represent an enhanced ability to initiate saccades beyond the mere warning benefits provided by the fixation offset. The effect appears to be most effective if the blank interval between fixation offset and target onset is approximately $200 \mathrm{~ms}$. The saccadic latency reduction produced by the temporal gap has been attributed to covert attentional processes (e.g., Fischer, 1987), overt orienting processes (e.g., Kingstone \& Klein, 1993a; Kingstone \& Klein, 1993b; Reuter-Lorenz, et al., 1991), facilitated sensory processing (e.g., Reulen, 1984), and oculomotor readiness (Saslow, 1967). Several researchers have examined the extent to which the gap effect reduces latencies of choice manual keypress responses. Iwasaki (1990) and Tam \& Stelmach (1993) found evidence of a gap effect with choice manual keypress responses. Importantly, however, these studies did not include an auditory warning tone that coineided with the visual fixation offset. Without an auditory warning tone, it is difficult to determine whether the reduced latencies were due to the gap effect or rather to a generalized warning effect provided by the offset of the fixation point (e.g., Tam \& Stelmach, 1993). Using a paradigm that included such an auditory warning tone, Reuter-Lorenz et al., (1991) did not find a gap effect for choice manual keypress responses. Tam \& Ono (1994) also did not find a gap effect with choice manual keypress responses (even without a warning tone). Thus, the evidence available so far indicates that fixation offset does not benefit the manual motor system unrelated to general warning effects.

As noted above, previous researchers examining manual gap effects all have used choice keypress responses (Iwasaki, 1990; Reuter-Lorenz. et al., 1991; Tam \& Ono, 1994; Tam \& Stelmach, 1993). However, saccades and keypress responses differ in two important ways. The first is that saccades are aimed, target-directed, spatially-oriented responses whereas keypresses are not. That is, subjects making a saccadic response must localize the target in space and produce an aimed response toward the target. On the other hand, with keypress responses, subjects typically have their fingers already placed on the keys, and they need to simply press the correct key upon receipt of the target signal. The other difference between eye movements and keypresses is that saccades are mutually exclusive: one can make either a saccade to the left or to the right but one cannot produce a saccade to go simultaneously to the left and right. Keypress responses are not mutually exclusive: one can easily press two keys simultaneously. These differences in the movements may reflect fundamental differences in the processes involved in planning and producing them. It may be that all aimed, mutually exclusive, spatially-oriented movements are sensitive to the gap effeet. If so, then advance offset of fixation (i.e., a gap) might facilitate aimed hand movements. Alternatively, it is possible that the gap effect is strictly an oculomotor phenomenon. In that case, even hand movements that were spatially-oriented would be expected to be unaffected by a gap.

\section{Experiment 1}

In this experiment, we explored the gap effect for manual responses. We used a manual response - $\mathrm{a}$ hand pointing movement- as similar as possible to a saccadic response. Pointing 
responses are spatially-oriented, aimed, and mutually exclusive. In the present experiment, subjects either made aimed hand responses, saccadic eye movement responses, or both hand pointing and saccadic responses to a peripheral target (similar to the methodology of Bekkering et al., 1994). By using such a design, we sought to: (1) replicate the gap effect when only saccade responses were required, (2) determine if the gap effect exists for hand pointing responses, and (3) determine the impact, if any, of simultaneous eye and hand movements on the gap effect. To control for the general warning benefits provided by the offset of the fixation point, an auditory warning tone was always presented prior to the presentation of the target stimulus.

\section{Method}

\section{Subjects}

Twelve Washington University (St. Louis, MO) students participated in an eighty-minute session. All subjects were right-handed, did not wear corrective lenses, and were naive with respect to the purpose of the study. Each subject was paid $\$ 10$ for their participation.

\section{Apparatus}

An IBM PC-AT computer controlled the presentation of stimuli and the acquisition of data throughout the experiment. The subject was seated at a table in a dark room with his/hes eyes $38 \mathrm{~cm}$ from a cathode-ray-tube (CRT) display. The subject's head was fixed by means of a dental-impression plate. The left eye was occluded, and the position of the right-eye was monitored with a scleral-reflectance device (Applied Science Laboratories, Model 210 ) mounted on a spectacles frame. The analog output from the eye-movement monitor was digitized at a rate of $1000 \mathrm{~Hz}$ with a resolution of 0.05 degrees. Calibration of the monitor was accomplished by taking samples while the subject fixated at each of 5 evenly spaced points across the CRT. Eye position was computed by using piecewise linear interpolation of the calibration points. Calibration was performed at the beginning of each session and verified before each trial. The subject's right elbow rested on a padded support on the table in front of him/her. They produced pointing movements by means of a handle which was mounted directly in front of and below the CRT. The handle, which was grasped in the right hand, moved from side to side along a low-friction track. A precision potentiometer attached to the track provided an analog signal indicating the position of the handle. This signal was digitized at a rate of $1000 \mathrm{~Hz}$ during the critical portions of each trial. A cardboard shield prevented the subjects from viewing their hand or the handle.

\section{Procedure}

The sequence of events on a trial is presented in Figure 1. At the beginning of each trial, subjects moved the handle so that it was aligned with a plus-sign at 0 degrees (straight ahead), In order to facilitate this alignment, a small. cursor appeared on the screen and moved in correspondence with the handle. Subjects were also required to fixate on the plus-sign. Following both the alignment of the handle and successful fixation, the plus-sign changed to 
a dot and the cursor was removed. Five hundred ms later, an auditory warning signal was presented for $50 \mathrm{~ms}$. In the gap condition, the dot was removed coincident with the offset of the warning signal. After an interval of $200 \mathrm{~ms}$ (the "gap"), a peripheral target then appeared either 10 degrees to the right or left of fixation. In the overlap condition, the dot remained visible for the $200 \mathrm{~ms}$ interval following the warning tone offset, followed by the appearance of the target (in the same manner as in the gap condition). In both conditions the target dot remained visible until the end of the trial. In the overlap condition, the fixation dot also remained visible until the end of the trial.

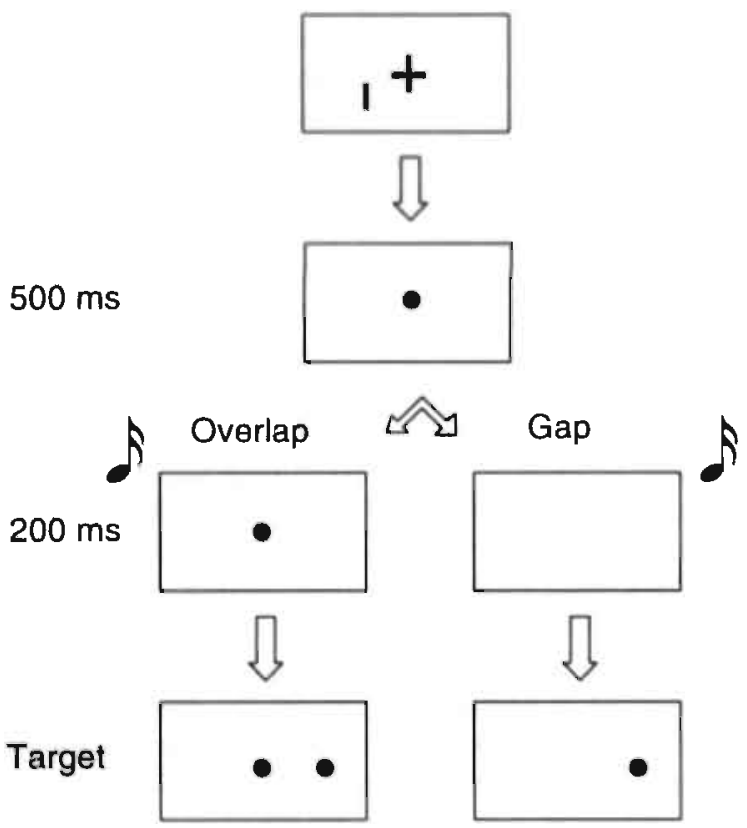

Figure 1. Sequence of events used in the present experiments. See the text for details.

Three different types of responses were studied: In the look-only condition, subjects made saccadic eye movements to the target but did not move the handle from the fixation location. 
In the point-only condition, subjects moved the handle to the target but were not permitted to move their eyes from the fixation location. In the look-and-point condition, subjects moved both their eyes and the handle to the target. Subjects were instructed to make all of their responses as quickly and as accurately as possible. Eyes and hands were monitored in all conditions to ensure that subjects only made the response appropriate to the condition.

\section{Design}

Subjects served in 2 blocks of 50 trials each for all 3 response conditions (look-only, point-only, look-and-point). The order of conditions was counterbalanced between subjects. In each block there were 25 gap and 25 overlap trials randomly presented. Targets were equally likely to appear to the right or left of fixation.

\section{Results}

For purposes of the analysis, the conditions which required a single response (look-only and point-only) were termed single-task while the look-and-point condition was termed dual-task. Latencies of eye and hand responses were analyzed using a 2 (task: single or dual) by 2 (response: eye or hand) by 2 (trial type: gap or overlap) by 2 (target: right or left) ANOVA. These data appear in Figure 2 (collapsed over targets). Overall, eye movements were initiated sooner than hand movements $(F(1,11)=59, p<.0001)$.

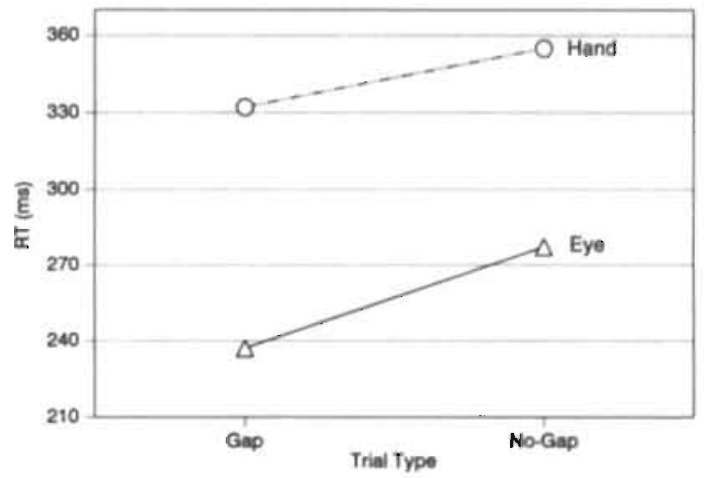

Figure 2. Mean latencies (ms) of saccadic cye and aimed hand movements in gap and overlap trials (Experiment I). A. robust, gap effect is demonstrated for both eye and hand responses.

Importantly, a main effect was found for trial type $(F(1,11)=34, p<.0001)$, with gap trials 
$(\mathrm{m}=284 \mathrm{~ms})$ faster than overlap trials $(\mathrm{m}=316 \mathrm{~ms})$. The task by trial type interaction was not significant $(F(1,11)<1.3, p>.27)$, indicating that the gap effect did not differ between the single- and dual-task conditions. However, the response by trial type interaction was significant $(F(1,11)=11, p<.005)$, with the gap effect being larger for eye movements $(\mathrm{m}=42 \mathrm{~ms})$ than for hand movements $(\mathrm{m}=25 \mathrm{~ms})$.

In order to further examine the gap effect, separate 2 (task) by 2 (trial type) by 2 (target) ANOVAs were conducted for eye and hand responses. The eye analysis revealed a significant gap effect $(F(1,11)=38, p<.0001)$ and that responses in the dual task were slower than those in the single task $(F(1,11)=8.0, p<.02)$. The task by trial type interaction was not significant $(F(1,11)<1)$. The hand analysis also revealed a significant gap effect $(F(1,11)=$ $20, p<.001)$ but no main effect for task $(F(1,11)<1)$ nor task by trial type interaction $(F(1,11)<1.2, p>3)$.

\section{Discussion}

The results of Experiment 1 clearly demonstrate that the gap effect facilitates the initiation of saccadic eye movements as well as the initiation of hand pointing movements. Moreover, the gap effect for hand movements was independent of the occurrence of eye movements. It seems unlikely that the gap effect found in this experiment can be solely attributed to a general warning effect of the visual offset because an auditory warning signal was presented $200 \mathrm{~ms}$ before the presentation of the target for both gap and overlap conditions. Thus, it appears that the gap effect is not limited to the oculomotor system. Additionally, hand latencies were not affected by simultaneous eye movements whereas eye latencies were detrimentally affected by simultaneous hand movements. This pattern of results replicates the previous findings of Bekkering et al., (1994) who also found an augmentation of eye latencies in a look-and-point condition compared to a look-only condition.

The size of the gap effect for both the eye and hand responses was unaffected by the presence or absence of simultaneous movement of the other system.

\section{Experiment 2}

The finding of a gap effect for hand pointing movements is in contrast to previous reports that have failed to find gap effects in the manual motor system. However, as noted earlier, these previous studies did not employ hand pointing movements but rather choice keypress responses. It may be that the gap effect only influences responses that are spatially oriented and mutually exclusive. In order to examine that possibility we studied a choice keypress response in the present experiment, in addition to the pointing movement from Experiment 1.

\section{Methods}

Subjects

Twelve Washington University (St. Louis, MO) students participated in a fifty-minute session. 
All subjects were right-handed, did not wear corrective lenses, and were naive with respect to the purpose of the study. Each subject was paid \$7 for their participation. None had participated in the previous experiment.

\section{Apparatus and Procedure}

The apparatus and procedure was identical to Experiment 1. Two conditions were used in Experiment 2. One condition was the point-only condition from Experiment 1. In the other condition, the choice condition, subjects were required to press the " $\mathrm{z}$ " key with their left hand in response to a target to the left of fixation and the "/" key with their right hand for a target to the right of fixation. Subjects were instructed to respond to the peripheral stimulus as quickly and as accurately as possible. The subject's eyes were monitored in both conditions to ensure that they did not look away from the fixation location.

\section{Design}

Subjects served in 2 blocks of 50 trials each for both conditions. Each condition included 25 gap and 25 overlap trials randomly presented. The order of conditions was completely counterbalanced between subjects. Targets were equally likely to appear to the left or right of fixation.

\section{Results}

Figure 3 shows latencies of aimed hand movements and choice manual keypress responses in gap and overlap trials (collapsed over target). The data were analyzed using a 2 (condition: point-only or choice) by 2 (trial type: gap or overlap) by 2 (target: right or left) ANOVA.

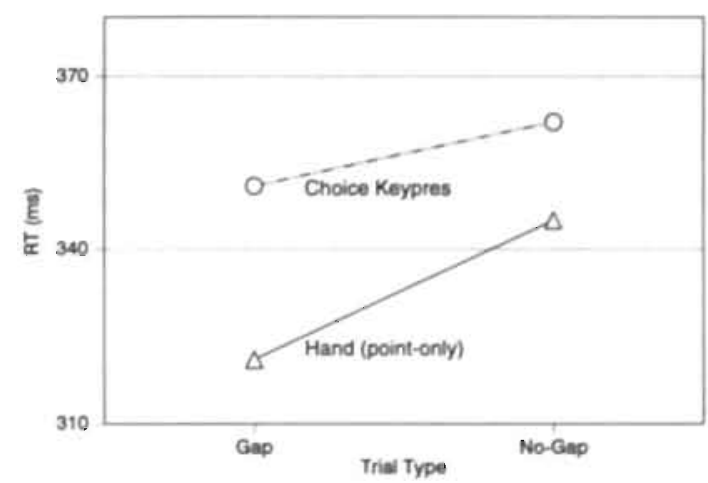

Figure 3. Mean latencies (ms) of aimed hand movements and choice manual keypress responses in gap and' overlap trials (Experiment, 2). A robust gap effect is demonstrated for hand responses, and a small, but reliable gap effect for choice manual keypress responses. 
Overall, no difference in latencies were found between the point-only and choice conditions $(F(1,11)<3.25, p>.09)$. A main effect for trial type was found $(F(1,11)=33, p$ $<.0001)$, indicating a significant gap effect. A significant condition by trial type interaction $(F(1,11)=15, p<.003)$ was found with the gap effect in the point-only condition ( $\mathrm{m}=24 \mathrm{~ms})$ larger than in the choice condition $(\mathrm{m}=11 \mathrm{~ms})$. Paired, two-tailed $\mathrm{t}$-tests indicated that there was a significant gap effect for both the point-only condition $(T(11)=5.98, p<.0001)$ and the choice condition $(T(11)=3.37, p<.006)$.

\section{Discussion}

Two major findings emerged from Experiment 2. First, a significant gap effect was again found for hand pointing movements, replicating the results from Experiment 1. Second, a smaller but significant gap effect was found for choice keypress responses. These two findings further suggest that the gap effect is not strictly an oculomotor phenomenon. However, the second result also suggests that mutually exclusive response alternatives are not necessary for a gap effect to occur. The finding of a gap effect for choice keypress responses opens the possibility that the reduced keypress latencies found by Iwasaki (1990) and Tam and Stelmach (1993) might not have been solely due to a generalized warning effect of a visual fixation offset, but instead may reflect a true gap effect. In the present experiments, the warning benefits of fixation offset were presumably also provided by the tone that was presented on all trials. As a result, we have assumed that any gap effect observed must reflect processes other than those involved in general alertness and warning effects. Nevertheless, it is possible that the warning available on gap trials (fixation offset plus tone) exceeded the warning benefits of the tone alone presented on the overlap trials. In order to examine this possibility, a third experiment was conducted.

\section{Experiment 3}

To test the possibility that the fixation offset served as a warning signal above and beyond the auditory warning signal, Experiment 3 compared choice keypress responses and simple keypress responses. If the visual offset does provide an additional warning benefit, then reduced latencies should be found in the gap condition for any response-- including both types of keypress responses studied here.

\section{Methods}

\section{Subjects}

Sixteen Washington University (St. Louis, MO) students participated in a fifty-minute session. All subjects were right-handed, did not wear corrective lenses, and were naive with respect to the purpose of the study. Each subject was paid \$7 for their participation. None had taken part in the previous experiments. 


\section{Apparatus and procedure}

The apparatus and procedure were identical to Experiment 1. Two conditions were used in Experiment 3. One condition was the choice condition from Experiment 2. In the other condition, the simple condition, subjects were required to press the spacebar with their right hand when the target appeared (regardless of the location of the target). Subjects were instructed to respond to the target stimulus as quickly and accurately as possible. The subject's eyes were monitored to ensure that they did not look away from the fixation location.

\section{Design}

Subjects served in 2 blocks of 50 trials each for both conditions. Each condition included 25 gap and 25 overlap trials randomly presented. The order of conditions was counterbalanced between subjects. Targets were equally likely to appear to the left and right of fixation.

\section{Results}

The latencies for the choice and simple conditions appear in Figure 4 (collapsed over target). The RTs were analyzed using a 2 (condition: choice or simple) by 2 (trial type: gap or overlap) by 2 (target: right or left) ANOVA.

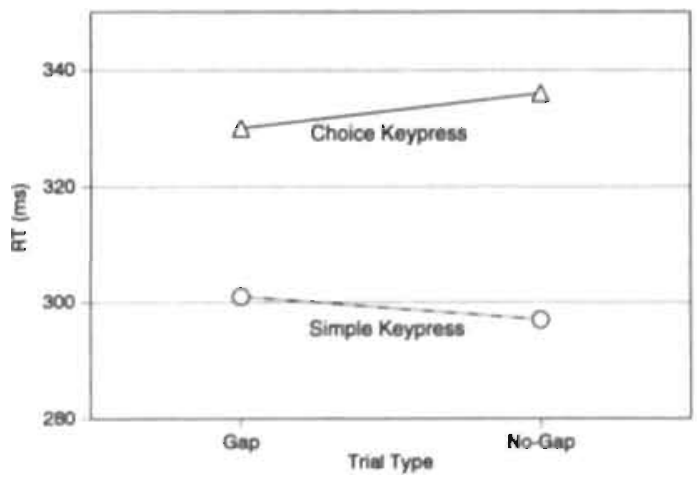

Figure 4. Mean latencies (ms) of choice manual keypress responses and simple manual keypress responses in gap and overlap trials (Experiment 3). A small but reliable gap effect is demonstrated for choice manual xeypress responses and no gap effect at all for simple manual keypress responses.

Overall, a main effect for condition was found $(F(1,15)=8.6, p<.01)$ with responses in the choice condition $(\mathrm{m}=333 \mathrm{~ms})$ slower than in the simple condition $(\mathrm{m}=299 \mathrm{~ms})$. No main effect for trial type was found $(F(1,15)<1)$. However, there was a significant condition 
by trial type interaction $(F(1,15)=5.3, p<.05)$ indicating a small gap effect for the choice condition $(6.3 \mathrm{~ms})$ and none for the simple condition $(-4.3 \mathrm{~ms})$. Two-tailed, paired t-tests confirmed a significant gap effect in the choice condition $(T(15)=2.2, p<.05)$ but not in the simple condition $(T(15)<1)$.

\section{Discussion}

If the gap effect found in the previous experiments was due to some general warning benefit provided by the fixation offset, then both choice and simple conditions should have exhibited gap effects. This was not the case, as only the choice condition showed a small but significant gap effect. Thus, it appears that only responses that have some goal-directed component exhibit gap effects. Although a choice keypress response has only a minimal goal-directed requirement (no precise localization of the target is required), a decision still has to be made with regard to direction. It appears that this minimum requirement of goal-directness is critical for the gap effect in manual responses.

\section{General discussion}

\section{Mechanisms underlying the gap effect}

The results of the present experiments shed some new light on the mechanisms underlying the gap effect. In particular, the gap effects for hand pointing movements in Experiments 1 and 2 indicate that the facilitatory effect of fixation offset carnot be attributed to processes exclusively within the oculomotor system. Moreover, the absence of a gap effect for simple manual keypress responses appears inconsistent with views that attribute the gap effect to attentional disengagement (e.g., Fischer 1987; Fischer \& Breitmeyer, 1987; Mayfrank et al., 1986). Attentional effects presumably occur early in visual processing (e.g., Hawkins, Shafto, \& Richardson, 1988) and are therefore likely to facilitate any type of response (e.g., Posner, 1980; Posner, Nissen, \& Ogden, 1978; Reuter-Lorenz, et al., 1991). Additionally, the absence of a gap effect for simple manual keypress responses suggests that the gap effect is not solely a general warning or preparation effect (e.g., Kingstone \& Klein, 1993a; 1993b; Ross \& Ross, 1980; 1981).

The present findings further indicate that the nature of the response modulates the size of the gap effect. The gap effect was smallest for choice keypress responses, larger for hand pointing, and largest for saccadic eye movements. It is possible that the more precise the spatial requirements of the response the greater facilitation provided by a fixation offset. The only response that was not spatial in nature, the simple keypress responses from Experiment 3, was the only response for which a gap effect was not found.

The question of why we found significant gap effects in choice keypresses responses while others had not is not clear. The present results suggest that the facilitated choice keypress latencies found with fixation offsets by Iwasaki (1990) and Tam \& Stelmach (1993) may have been due to the gap effect or a warning signal effect. However, Reuter-Lorenz et al., (1991) and Tam \& Ono (1994) failed to find any facilitation with a fixation offset for keypress response latencies. Nevertheless, a close inspection of the Reuter-Lorenz et al., (1991) and Tam 
\& Ono (1994) data reveals faster choice RTs with fixation offset in both studies, although these facilitatory effects were not statistically significant. Both studies used relatively small numbers of subjects; five subjects in Experiment 1 of Reuter-Lorenz et al.,(1991) and five subjects each in Experiments 2 and 3 of Tam \& Ono (1994). It may be that the relatively small number of subjects rendered these studies somewhat less sensitive to gap effects. Supporting this notion is the fact that the choice keypress latencies in Experiment 2 of Tam \& Ono (1994) were 17 $m s$ faster with a fixation offset, an effect size larger than the two significant choice keypress gap effects found in the present study using 12 subjects each $(11 \mathrm{~ms}$ and $6.3 \mathrm{~ms})$.

\section{Role of the Superior Colliculus in the gap effect}

There is accumulating neurophysiological evidence that the superior colliculus (SC) forms part of a system that facilitates active visual fixation (e.g., Munoz \& Wurtz, 1992) and that the SC is essential for the generation of short latency saccades that are produced in the gap paradigm (e.g., Munoz \& Wurtz, 1992; Schiller, Sandell \& Maunsell, 1987). Additionally, Goldberg, Bushnell, and Bruce (1986) demonstrated that the threshold needed to elicit a saccade from the SC increases during active fixation. The contribution of the SC to the gap-effect is also consistent with the finding that the facilitatory effect appears to be limited to prosaccade, not anti-saccade, latencies. This is because the SC does not appear to control other responses than saccadic eye movements toward a desired object (e.g., Reuter-Lorenz, et al., 1991).

At first, the present findings of an aimed hand gap effect seems to be in conflict with the SC interpretation of the gap effect. However, Werner (1993) has recently reported neuronal activity in the primate SC before and during arm movements to visual targets. Werner (1993) further noted that "It is likely that the primate superior colliculus is not only involved in the initiation and control of orienting movements of the eyes but also in reaching movements of the arms." (p. 335). It might be that the SC is involved in all types of orienting movements towards external targets because it receives convergent input from visual, auditory and somatosensory cortical areas. Consistent with this interpretation is the finding that projections have been found from the arm representation area of motor and premotor cortex to deep layers of the SC (Fries, 1984; 1985).

Additional work will be needed to further elucidate the complex interrelations between the various orienting and movement production systems, and the role that the SC may play in those behaviours. We consider that the present study represents a step in that direction. 


\section{References}

Abrams, R.A., Meyer, D.E., \& Kornblum, S. (1990). Eye-hand coordination: Oculomotor control in rapid aimed limb movements. Journal of Experimental Psychology: Human Perception and Performance, 14, 428-443.

Bekkering H, Adam J.J., Kingma H., Huson A., \& Whiting, H.T.A. (1994). Reaction time latencies of eye and hand movements in single and dual-task conditions. Experimental Brain Research, 97, 471-476.

Bekkering, H., Abrams, R.A., \& Pratt, J. (manuscript under review). Transfer of saccadic adaptation to the manual motor system. Human Movement Science.

Bekkering H, Adam J.J., Kingma H., van den Aarssen, A., \& Whiting, H.T.A. (manuscript under review). Interference effect between the initiation of saccadic eye and goal-directed hand movements. Experimental Brain Research.

Fischer, B. (1987). The preparation of visually guided saccades. Reviews of Physiology. Biochemistry and Pharmacology, 106, 1-35.

Fischer, B, \& Breitmeyer, B. (1987). Mechanisms of visual attention revealed by saccadic eye motions. Neuropsychologica, 25, 73-83.

Fischer, B., \& Ramsperger, E. (1984). Human express saccades: Extremely short reaction times of goal-directed eye movements. Experimental Brain Research, 57, 191-195.

Fries, W. (1984). Cortical projections to the superior colliculus in the macaque monkey: a retograde study using peroxidase. Journal of Comparative Neurology, 230, 55-76.

Fries, W. (1985). Inputs from the motor and premotor cortex to the superior colliculus in the rhesus monkey. Behavioural Brain Research, 18, 95-105.

Goldberg, M.E., Bushnell, M.C., \& Bruce, J.C. (1986). The effect of attentive fixation on eye movements evoked by electrical stimulation of the frontal eye fields. Experimental Brain Research, 61, 579-584.

Hawkins, H.L., Shafto, M.G., \& Richardson, K. (1988). Effects of target luminance and cue validity on the latency of visual detection. Perception \& Psychophysics, 44, 484-492.

Iwasaki, S. (1990). Facilitation of reaction times with gap paradigm: Comparison of manual and saccadic responses. Ergonomics, 33, 833-850.

Kingstone, A., \& Klein, R. (1993a). Visual offset facilitate saccadic latency: Does pre-disengagement of visouspatial attention mediate this gap effect? Journal of Experimental Psychology: Human Perception and Performance, 19, 125il-1265.

Kingstone, A., \& Klein, R. (1993b). What are human express saccades? Perception \& Psychophysics, 54, 260-273.

Mayfrank, L., Mobashery, M., Kimmig, H., \& Fischer, B. (1986). The role of fixationandvisual attention in the occurence of express saccades in man. European Archives of Psychiatry \& Neurolical Sciences, 235, 269-275.

Munoz, D.P., \& Wurtz, R.H. (1992). Role of the rostral superior colliculus in active fixation and execution of express saccades. Journal of Neurophysiology, 67, 1000-1002.

Nemire, K., \& Bridgeman, B. (1987). Oculomotor and skeletal motor systems share one map of visual space. Vision Research, 27, 393-400.

Posner, M.I. (1980). Orienting of attention. Quarterly Journal of Experimental Psychology, 32, 3-25.

Posner, M.I., Nissen, M.J., \& Ogden, W.C. (1978). In H.L. Pick \& I.J. Saltzman (Eds.), Attended and unattended processing modes: The role of set for spatial location. Models of perceiving and information processing. Hillsdale, NY: Erlbaum

Reulen, J.P.H., (1984a). Latency of visually evoked saccadic eye movements: I. Saccadic latency and the facilitation model. Biological Cybernetics, 50, 251-263.

Reulen, J.P.H., (1984b). Latency of visually evoked saccadic eye movements: II. Temporal properties of the facilitation mechanism. Biological Cybernetics, 50, 263-271.

Reuter-Lorenz, P., Hughes, H., \& Fendrich, R. (1991). The reduction of saccadic latency by prior offset of the fixation point: An analysis of the gap effect. Perception \& Psychophysics, 49, 167-175.

Ross, L.E., \& Ross, S.M. (1980). Saccade latency and warning signals: Stimulus onset, offset, and change as warning events. Perception \& Psychophysics, 27, 263-271.

Ross, L.E., \& Ross, S.M. (1981). Saccade latency and warning signals: Effects of auditory and visual stimulus onset and offset. Perception \& Psychophysics, 29, 429-437. 
Saslow M.G. (1967). Latency for saccadic eye movement. Journal of Optical Sociefy of America, 57, 1030-1033. Schiller, P.H., Sandell, J.H., \& Maunsell, J.H.R. (1987). The effect of frontal eye field and superior colliculus lesions on saccadic latencies in the rhesus monkey. Journal of Neurophysiology, 57, 1033-1049.

Tam, W., \& Stelmach, L. (1993). Viewing behavior: Ocular and attentional disengagement. Perception \& Psychophysics, 54, 211-222.

Tam, W., \& Ono, H. (1994). Fixation disengagement and eye-movement latency. Perception \& Psychophysics, 56" 251-260.

Werner, W. (1993). Neurons in the primate superior colliculus are active before and during arm movements to visual targets. European Journal of Neuroscience, 5, 335-340. 
60 


\section{5 \\ The gap effect for spatially oriented responses}

\section{Summary}

A temporal gap between fixation point offset and stimulus onset results in shorter saccadic latencies than if the fixation point remains on. Recently, a gap effect for aimed hand movements was found independent of whether the hand moved alone or was accompanied by a saccadic eye movement. However, no gap effect was found for simple keypress responses. This may have been because spatially oriented eye and hand movements demand more complex response-preparation processes as well as more complex response-execution processes than do simple keypress responses. The present study manipulated target uncertainty to investigate whether the gap effect for spatially oriented eye and hand movements is related to facilitation of response-preparation processes or to response-execution processes. The finding of robust gap effects for eye and aimed hand movement responses independent of response-preparation mechanisms (i.e. target uncertainty) is consistent with an interpretation of the gap effect in terms of facilitation of response-execution processes associated with spatially oriented eye and hand movement responses.

\section{Introduction}

In order to interact effectively with the immediate environment, human beings must orient themselves toward specific spatial locations. Reaching for the telephone, reading the newspaper, indeed, almost every overt behaviour that human beings produce involves some kind of spatially oriented behaviour. It has long been known that advance offset of a visual fixation point facilitates initiation of oriented, saccadic eye movements to peripherally presented visual target stimuli (Saslow, 1967). This robust finding of reduced eye latencies in case of a temporal gap between fixation point offset and stimulus onset has been referred to as the "gap effect". The gap effect appears to be most effective when the blank interval between fixation offset and target onset is approximately $200 \mathrm{~ms}$.

The saccadic latency reduction produced by the temporal gap has been attributed to covert attentional processes (e.g., Fischer, 1987), facilitated sensory processing (e.g., Reulen, 1984a; 1984b), and oculomotor readiness (Saslow, 1967). Recently, an explanation of the gap effect has been. advanced in terms of overt oculomotor processes effect (Kingstone \& Klein, 1993a, 1993b, Reuter-Lorenz et al., 1991; Tam \& Stelmach, 1993; Tam \& Ono, 1994). This

\footnotetext{
- Submitted to Acta Psychologica. Co-authors: J. Pratt, J.J. Adam and R.A. Abrams.
} 
interpretation assumes that during eye fixation the oculomotor system is effectively locked or engaged on the fixation target and that voluntary shifts of fixation and reflexive glances toward novel objects are inhibited (e.g., Guitton et al., 1985). Extinguishing the fixation point facilitates saccadic latencies by breaking the processes that maintain the eye directed at the fixation point. However, Bekkering, Pratt and Abrams (under review) found that the gap effect also facilitates the initiation of hand pointing movements. Importantly, the hand gap effect was also found in a condition where subjects were not permitted to move the eyes from the fixation location. Thus, it appears that the gap effect is not limited to the oculomotor system.

Interestingly, no gap effect was found for simple key press responses by Bekkering et al. (under review). In the simple keypress condition, there was only one key which subjects had to press upon receipt of the target stimulus. Saccadic eye and aimed hand movements, on the other hand, demand at least two additional components. First, subjects localized the correct target position in space and, subsequently, prepared the response in order to look and/or point to the target. Second, subjects executed the response toward the target location. This may suggest that the occurrence of the gap effect is either related to more complex responsepreparation processes or to more complex response-execution processes. By response preparation, we mean the decisions that a person needs to make in order to specify features such as amplitude and direction of the upcoming movement. There is ample evidence that at least some of these parameters of a response can be specified in advance of the imperative signal (Abrams \& Jonides, 1988; Rosenbaum, 1980). By response exection we mear the processes associated with actually executing the motor program--sending the commands to the muscles to produce the planned movement. These are the processes that would be involved in producing force pulses in eye and hand muscles of the precise magnitude and duration in order to move the eye or limb to the desired target (e.g., Abrams, Meyer, \& Kornblum, 1989; Meyer, Smith, Whright, 1982).

One way to differentiate between a response-preparation versus a response-execution locus of the gap effect is to manipulate target uncertainty. Certainty about target location was manipulated in the present experiment by having the peripheral target appear randomly to the left or right of fixation (uncertain condition) or by having the subjects know in advance where the target would appear (certain condition). If subjects know in advance where the target would appear, then they should be able to prepare the response in advance of the latency interval. If the gap effect typically reduces saccade latencies by facilitation response preparation processes, then the gap effect should be dramattically reduced if subjects are aware of the target location in advance. However, if the gap effect is due to facilitated response execution processes, then the gap effect should be the same magnitude regardless of the certainty of the upcoming target location.

Thus, response-preparation processes were reduced in the certain condition relative to the uncertain condition, while response-execution processes were similar in both conditions. Subjects were required to move their eye and hand alone or concurrently towards the target in order to investigate the impact of the target uncertainty manipulation separately for the two motor systems.

\section{Method}

Subjects 
Twelve Washington University (St. Louis, MO) students participated in an eighty-minute session, 6 in the uncertain condition and 6 in the certain condition. All subjects were right-handed, did not wear corrective lenses, and were naive with respect to the purpose of the study. Each subject was paid $\$ 10$ for their participation.

\section{Apparatus}

An IBM PC-AT computer controlled the presentation of stimuli and the acquisition of data throughout the experiment. The subject was seated at a table in a dark room with his/her eyes $38 \mathrm{~cm}$ from a cathode-ray-tube (CRT) display. The subject's head was fixed by means of a dental-impression plate. The left eye was occluded, and the position of the righi-eye was monitored with a scleral-reflectance device (Applied Science Laboratories, Model 210) mounted on a spectacles frame. The analog output from the eye-movement monitor was digitized at a rate of $1000 \mathrm{~Hz}$ with a resolution of 0.05 degrees. Calibration of the monitor was accomplished by taking samples while the subject fixated at each of 5 evenly spaced points across the CRT. Eye position was computed by using piecewise linear interpolation of the calibration points. Calibration was performed at the beginning of each session and verified before each trial. The subject's right elbow rested on a padded support on the table in front of him/her. Subjects produced pointing movements by means of a handle which was mounted directly in front of and below the CRT. The handle, which was grasped in the right hand, moved from side to side along a low-friction track. A precision potentiometer attached to the track provided an analog signal indicating the position of the handle. This signal was digitized at a rate of $1000 \mathrm{~Hz}$ during the critical portions of each trial. A cardboard shield prevented the subjects from viewing their hand or the handle.

\section{Procedure}

The sequence of events on a trial is presented in Figure 1. At the beginning of each trial, subjects moved the handle so that it was aligned with a plus-sign at 0 degrees (straight ahead). In order to facilitate this alignment, a small cursor appeared on the screen and moved in correspondence with the handle. Subjects were also required to fixate on the plus-sign. Following both the alignment of the handle and successful fixation, the plus-sign changed to a dot and the cursor was removed. Five hundred ms later, an auditory warning signal was presented for $50 \mathrm{~ms}$ to control for the general warning benefits provided by the offset of the fixation point. In the gap condition, the dot was removed coincident with the offset of the warning signal. After an interval of $200 \mathrm{~ms}$ (the "gap"), a peripheral target appeared. In the overlap condition, the dot remained visible for the $200 \mathrm{~ms}$ interval following the warning tone offset, followed by the appearance of the target. In both conditions the target dot remained visible until the end of the trial. In the overlap condition, the fixation dot also remained visible until the end of the trial. The targets appeared either 10 degrees to the left or right of fixation. In the uncertain condition the target appeared randomly at either location. In the certain condition the target appeared at one location for the first half of the experiment and at the other location for the second half of the experiment. Subjects in the certain condition were informed about the target location in advance. However, catch trials were also presented to prevent anticipatory eye and/or hand responses. 


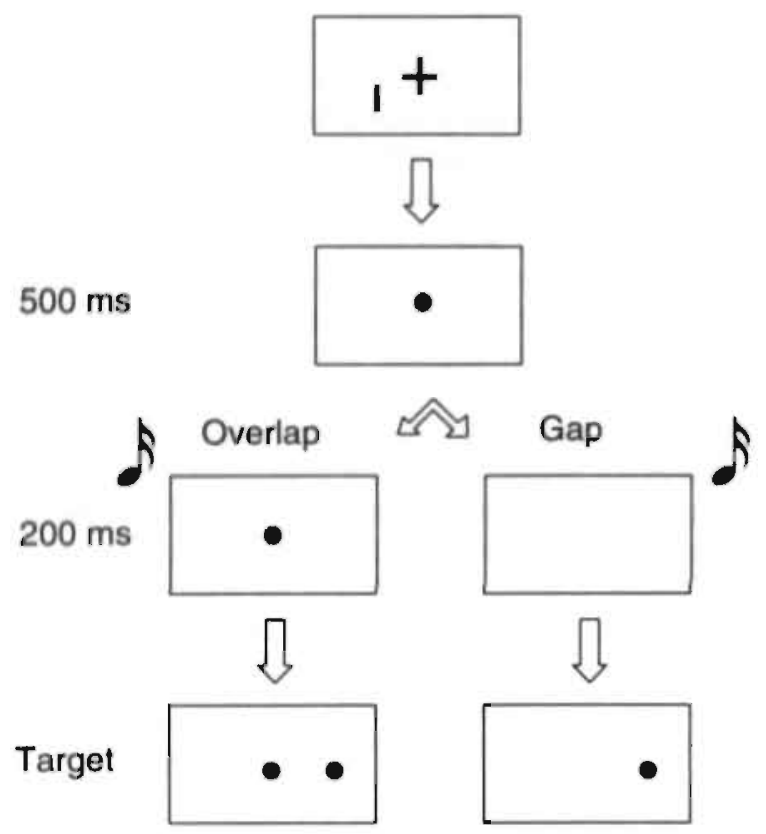

Figure 1. Sequence of events used in the present experiments identical to Fig. 1 of Chapter 4, see the text for details.

Three different types of responses were studied: In the look-only condition, subjects made saccadic eye movements to the target but did not move the handle from the fixation location. In the point-only condition, subjects moved the handle to the target but were not permitted to move their eyes from the fixation location. In the look-and-point condition, subjects moved both their eyes and the handle to the target. Subjects were instructed to make all of their responses as quickly and as accurately as possible. Eyes and hands were monitored in all conditions to ensure that subjects only made the response appropriate to the condition. 


\section{Design}

The subjects in the uncertain condition served in 2 blocks of 50 trials each for all 3 response conditions (look-only, point-only, look-and-point). The order of conditions was counterbalanced between subjects. In each block there were 25 gap and 25 overlap trials randomly presented. Targets were equally likely to appear to the right or left of fixation.

The subjects of the certain condition served in 2 blocks of 70 trials each for all 3 response conditions (look-only, point-only, look-and-point). The order of conditions was counterbalanced between subjects. In each block there were 25 gap trials, 25 overlap trials and 20 catch trials presented. In the catch trials no target stimulus was presented and subjects were not allowed to move their eye or hand. A beep indicating an error was presented whenever a subject moved his or her eye or hand on a catch-trial. Targets appeared in the first half of the trials always either to the left or right of fixation and in the second half of the trials vice versa. The order of left and right target presentation was counterbalanced between subjects.

\section{Results}

Latencies of eye and hand responses were analyzed using at split-plot analysis of variance (ANOVA) with target uncertainty (choice or simple) as between subjects variable and task (single or dual), response (eye or hand), and trial type (gap or overlap) as within subjects variables. These data appear in Figure 2 for the uncertain and certain condition, collapsed over task.

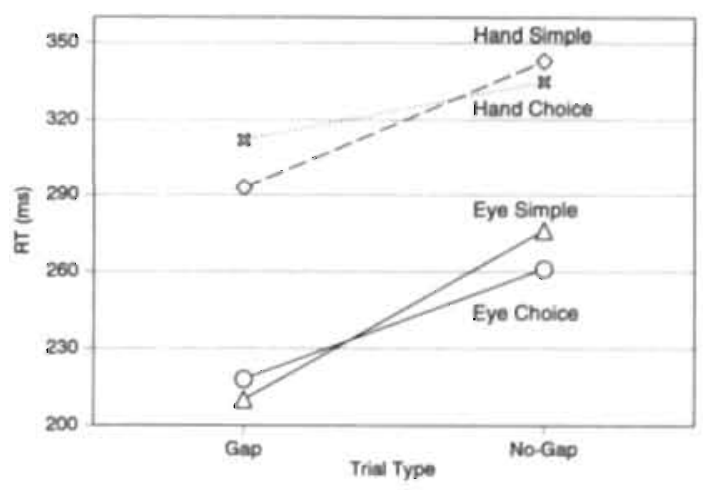

Figure 2. Mean latencies (ms) of saccadic eye and aimed hand movements and choice manual keypress. responses in gap and overlap trials for the uncertain condition - target stimuli appeared randomly to the left or right of fixation - and for the certain condition - target stimuli appeared in fixed blocks to the left or right of fixation. A robust gap effect is demonstrated for eye and hand responses in both conditions. 
Importantly, no significant difference was found for target uncertainty $(F(2,10)<1)$, indicating similar latencies in the uncertain and certain condition. In addition, no significant interactions between target uncertainty and the other factors (all $p$ 's $>.05$ ) were found, indicating that target uncertainty had a similar influence on eye and hand responses, on gap and overlap trials, and on single- and dual-task conditions. The only trend that was observed was an interaction between target uncertainty and trial type $(F,(2,10)=3.3, p<.10$, hinting that the gap effect might be larger in the certain condition than in the uncertain condition. Overall subjects inhibited their movements in $83 \%$ of all catch-trials.

Overall, eye movements were initiated sooner than hand movements $(F(2,10)=40, p$ $<.0001)$, in addition, a main effect was found for trial type $(F(2,10)=41, p<.0001)$, with gap trials $(\mathrm{m}=264 \mathrm{~ms})$ faster than overlap trials $(\mathrm{m}=303 \mathrm{~ms})$. The only other significant finding was the movement by trial type interaction $(F(2,10)=13, p<.004)$, indicating that the gap effect was larger for eye movements ( $54 \mathrm{~ms}$ ) than for hand movements ( $37 \mathrm{~ms})$.

\section{Discussion}

\section{Mechanisms underlying the gap effect}

The present results clearly corroborate our previous findings of gap effects for both saceadic eye and aimed hand movements in case of randomly presented target stimuli. Thereby indicating that the gap effect occurs for aimed hand movements in addition to saccadic responses (Bekkering et al., under review). Moreover, in the present study, robust gap effects were found for eye and hand responses when subjects knew in advance where the target would appear. The finding of gap effects for eye and hand responses independent of complexity of response-preparation mechanisms, i.e. target uncertainty, is consistent with a response-execution interpretation of the gap effect. Thus, the gap effect is due at least partly to factors that influence the execution of the response.

The notion that the gap effect may be due to response-execution processes may also explain why Bekkering et al (under review) did not find such an effect with simple keypress responses, a condition also with no response-uncertainty. Simple keypress responses do not require a spatially directed response, whereas the looking and pointing in the present experiment always required such a response, even when the location was completely certain. It appears that response-execution processes involved with movements to spatially localized targets are essential for reducing latencies with visual fixation offsets.

This latter conclusion is also consistent with the findings of several other researchers who have studied the gap effect. For example, Fendrich, Hughes, and Reuter-Lorenz (1991) found that advance offset of fixation facilitated saccades to auditory target locations. Under those conditions, there was no visible target, yet subjects were still required to produce spatially oriented responses. Additionally, Abrams, Oonk, and Pratt (under review) have reported the presence of a gap effect for endogenous saccadic eye movements--saccades directed toward a pheripheral target, but signalled by a central signal.

However, the results of the present study also suggest that response-preparation processes did have some influence on the magnitude of the gap effect. Figure 2 reaveals a trend 
towards larger gap effects in the certain condition than in the uncertain condition. It may have been that because subjects in the certain condition knew what to do and where to go, they may have been able to optimally prepare parameters for the execution of eye and hand responses in the time between fixation offset and stimulus onset.

Thus, although the gap effect appears to be largerly due to response-execution processes, it may also be influenced to a lesser extent by response-preparation processes.

\section{Catch trials}

Interestingly, eye and hand latencies in the certain condition were similar to those in the uncertain condition, while typically, latencies of eye (Carpenter, 1988) and hand (e.g., Christina et al., 1982; Sideaway 1991; Sideaway et al., 1988) movements are shorter in the simple condition than in the choice condition, i.e. simple and choice RTs. In the present experiment, the RT latencies in the certain condition might have been prolonged due to the employment of catch trials. Catch trials, i.e. trials in which the stimulus is not presented, were used to prevent subjects from anticipation. A well known side-effect of catch-trials is that responses which follow catch trials tend to be slower than those following target trials (e.g., Juttner \& Wolf, 1992; 1994; Kingstone \& Klein, 1993). Consequently, latencies in the simple condition might have been slower than typically observed.

In conclusion, the present study provides evidence for 3 main points. First, by corroborating Bekkering et al. (1994), there is now converging evidence that the gap effect occurs for both oculomotor and skeletal motor responses. Second, the results suggest that the gap effect for eye and hand responses is largely due to response-execution processes. Finally, the results suggest that response-preparation processes may have a small influence on the gap effect. It is our hope that further work will determine the exact role of the various responseexecution and response-preparation processes that are present in the gap effect. 


\section{References}

Abrams, R.A., \& Dobkin, R.S. (1994). The gap effect and inhibition of return: Interactive effects on eye movement latencies. Experimental Brain Research, 98, 483-483.

Abrams, R.A. \& Jonides, J. (1988). Programming saccadic eye movements. Journal of Experimental Psychology: Human Perception and Performance, 14, 428-443.

Abrams, R.A., Oonk, H., \& Pratt, J. (manuscript under review). Fixation point offsets facilitate endogenous saccades.

Bekkering. H., Pratt, J. \& Abrams, R.A., (manuscript under review). The gap effect for eye and hand movement. Perception \& Psychophysics.

Christina, R.W., Fischman, M.G., Vercruyssen, M.J.P., \& Anson, J.G. (1982). Simple reaction time as a function of response complexity: Memory drum theory revisted. Journal of Motor Behavior, 14, 301-321.

Fischer, B. (1987). The preparation of visually guided saccades. Reviews of Physiology, Biochemistry and Pharmacology, 106, 1-35.

Juttner, M., \& Wolf, W. (1992). Occurence of human express saccades depends on stimulus uncertainty and stimulus sequence. Experimental Brain Research, 89, 678-681.

Kingstone, A., \& Kiein, R. (1993a). Visual offset facilitate saccadic latency: Does predisengagement of visouspatial attention mediate this gap effect? Journal of Experimental Psychology: Human Perception and Performance, 19, 1251-1265.

Kingstone, A., \& Klein, R. (1993b). What are human express saccades? Perception \& Psychophysics, 54, 260-273.

Reulen, J.P.H., (1984a). Latency of visually evoked saccadic eye movements: I. Saccadic latency and the facilitation model. Biological Cybernetics, 50, 251-263.

Reulen, J.P.H., (1984b). Latency of visually evoked saccadic eye movements: I1. Temporal properties of the facilitation mechanism. Biological Cybernetics, 50, 263-271.

Reuter-Lorenz, P., Hughes, H, \& Fendrich, R. (199i). The reduction of saccadic latency by prior offset of the fixation point: An analysis of the gap effect. Perception \& Psychophysics, 49, 167-175.

Saslow M.G. (1967). Lateney for saccadic eye movement. Journal of Optical Society of America, 57, 1030-1033.

Sideaway B, Christina RW, Shea JB (1988) A movement constraint interpretation of the response complexity effect and programming time. In A Colley \& J Beechs (eds) Cognition and action in skilled behaviour. Amsterdam: North-Holland, pp 87-102.

Sideaway B (1991) Motor programming as a function of constraints on movement initiation. Journal of Motor Behavior, 23, 120-130. 


\section{6 \\ Transfer of saccadic adaptation to the manual motor system}

\section{Summary}

When a saccade target is shortened in amplitude during the eye movement towards it, subjects will initially overshoot the displaced target and make secondary movements to fixate it. Nevertheless, after a few trials the eye adapts and goes directly to the final displaced target position. The aim of the present study was to examine whether hand pointing will be influenced by saccadic adaptation. We found that pointing movements of an unseen hand were shorter when the eye was adapted compared to when the eye was unadapted, thus demonstrating a transfer of the modification of the oculomotor system to the manual motor system. These results have important implications for the mechanisms that underlie goal-directed eye and hand movements. In particular, it seems that the two systems may use a common signal to specify eye and arm localization.

\section{Introduction}

In order to reach for an object in their surroundings, an actor must transform the sensorial information about the target into an appropriate set of commands for the muscles needed to reach for or point to the object. This, of course, is needed in addition to an internal representation of the location of our body and the objects around us (e.g., Blouin et al., 1993; Flanders et al., 1992; Graaf de, 1994; Jeannerod, 1988; Paillard, 1991). Typically, such a limb movement is accompanied by a saccadic eye movement (e.g., Abrams et al., 1990; Bekkering et al., 1994; Biguer et al., 1982; Fischer \& Rogal, 1986; Mather \& Fisk, 1985; Prablanc et al., 1986).

A considerable amount of work has been done regarding a possible common source of spatial information for the skeletalmotor and oculomotor systems (e.g., Gielen et al., 1984; Nemire \& Bridgeman, 1987; Prablanc et al., 1979). Despite this work, it is still not clear whether hand and eye use two independent spatial representations to produce movements, or whether eye and hand movements are controlled from a common source. Gielen et al., (1984) found similar end positions for eye and arm movements, and concluded that the program generators for the arm and eye movements share a common command signal. Also, Nemire \& Bridgeman (1987) found that manipulating the oculomotor system independently from the manual system - in one condition subjects had

"Human Movement Science (in press). Co-authors: R.A. Abrams and J. Pratt. 
to make 40 saccadic eye movements before attempting to look and point where the target disappeared, while in another condition they had to maintain fixation for $20 \mathrm{sec}$ following target offset - resulted in similar changes in the output of both systems. However, Prablanc et al., (1979), found that when the peripheral target was removed at the onset of the saccade, there was no correlation between the error of gaze position and the error of hand pointing.

The present study continues in this spirit, focusing on the change that may occur in the output of one motor system as a consequence of a change in the output of the other system. Specifically, we examined whether hand pointing is influenced by adaptive modification of saccadic eye movements.

It is well known that displacing the target for a saccade during the eye movement will eventually change the saccadic eye movement (e.g., Abrams et al., 1992; Deubel et al., 1986; Henson, 1978; Frens \& Opstal van, in press; McLaughlin 1967; McLaughlin et al., 1968; Miller et al., 1981). Typically, subjects will initially miss the displaced target and then make secondary, corrective movements to fixate it. Interestingly, the eye soon adapts and goes directly to the final displaced target position. The aim of this study is to determine whether there is transfer of this eye adaptation to the skeletal motor system. In order to examine this, the present experiment employed an adaptation paradigm similar to that used previously by us and others (e.g., Abrams et al., 1992; Miller et al., 1981; Semmlow et al., 1989) but with several modifications designed to enhance the amount of eye adaptation and also to minimize the typical large standard errors of pointing measures.

\section{Method}

\section{Subjects}

Six Washington University (St. Louis, MO) students each served in four sessions on separate days. Each session contained two blocks of trials of approximately 30 minutes each with a break of at least 5 minutes between the blocks. All subjects were right-handed and were naive with respect to the purpose of the study. Each subject was paid $\$ 30$ for their participation.

\section{Apparatus}

An IBM PC-AT computer controlled the presentation of stimuli and the acquisition of data throughout the experiment. Each subject was seated at a table in a dark room with their eyes $38 \mathrm{~cm}$ from a cathode-ray-tube (CRT) display. The subject's head was fixed by means of a dental-impression plate. The left eye was occluded, and the position of the right-eye was monitored with a scleral-reflectance device (Gulf \& Western, Model 200) mounted on a spectacles frame. The analog output from the eye-movement was digitized at a rate of $1000 \mathrm{~Hz}$ with a resolution of $0.05^{\circ}$. Calibration of the monitor was done by iaking samples while the subject fixated at each of 5 evenly spaced points across the CRT. Eye position was computed by using piecewise linear interpolation of the calibration points. Calibration was performed at the beginning of each session and verified before each trial. The subject's right elbow rested on a padded support on the table in front of them, and they grasped a handle in their right hand. The handle was mounted directly in 
front of and below the CRT. Subjects moved the handle in order to make pointing responses. A shield prevented the subjects from viewing their hand.

\section{Procedure}

At the beginning of each trial, a small fixation cross and the target dot appeared either at $8^{\circ}$ or $10^{\circ}$ to the right of the fixation cross - see text below and Fig. I for further explanation - were simultaneously presented. Afterwards, subjects moved the handle to a small fixation cross at $0^{\circ}$ (straight ahead) with the aid of auditory stimuli controlled by the computer. When the handle was at the appropriate starting position, subjects fixated the cross, and then $1000 \mathrm{~ms}$ later the cross changed to a dot, indicating successful fixation. One thousand ms later, the fixation dot disappeared, signalling subjects to make both a saccadic eye movement and a hand pointing movement to the target. Subjects were instructed to look and point to the target as accurately as possible but without pressure to minimize their latencies.

Saccades and hand pointing movements were obtained on test trials in two phases of the experiment: during either a block of control trials or a block of adaptation trials. The sequence of events on each of these types of trials is shown in Figure 1.
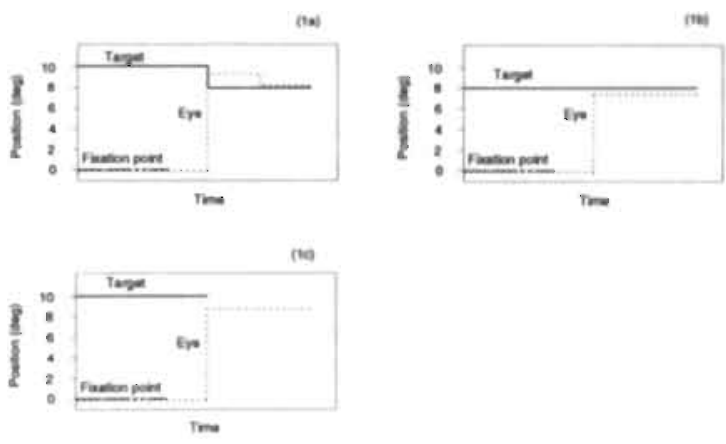

Figure 1. Sequence of events on trials in experiment. Ia: Events in the adaptation phase, the target jumped from $10 \mathrm{deg}$ (to the right of fixation) to $8 \mathrm{deg}$ at the onset of eye movements. Ib:Events in the control phase, the target appeared and remained at $8 \mathrm{deg}$. Ic: Events on test trials, the target appeared at $10 \mathrm{deg}$, but disappeared at the onset of the eye movement.

In the control trials, subjects looked and pointed to a target $8^{\circ}$ to the right of the fixation location'. In the adaptation trials, subjects looked and pointed to a target $10^{\circ}$ to the right

\footnotetext{
${ }^{1}$ The 8 degree control target was chosen so that even in the case of maximal adaptation, the movements in the control block were at least as short as the movements in the adaptation blocks.
} 
of the fixation. However, in this phase the target jumped from $10^{\circ}$ to $8^{\circ}$ at the onset of the eye movement (defined as the first moment in time at which the position of the eye differed by more than $1.5^{\circ}$ from its position during the first $10 \mathrm{~ms}$ after the offset of the fixation point). The relatively small $2^{\circ}$ jump was used to reduce the possibility that subjects would notice the step (Bridgeman et al., 1975). In both the control and adaptation trials, the target remained illuminated for $1000 \mathrm{~ms}$. In the critical test trials, the target appeared $10^{\circ}$ to the right of fixation but disappeared at the onset of the saccade. Thus, in the test trials, subjects received no retinal information regarding the accuracy of the eye and the hand movements. Note that the test trials were the same regardless of whether they followed the control or the adaptation trials.

\section{Design}

At the first session, the subjects were first given 2 practice blocks, each consisting of 6 control trials and 6 test trials. All other sessions started with 1 practice block. Data from these trials are not included in the analysis. Following the practice sessions, subjects then performed either a control block, containing 24 control trials followed by 5 sequences each consisting of 8 control trials and 4 test trials or an adaptation block, containing 24 . adaptation trials followed by 5 sequences of 8 adaptation trials and 4 test trials. Thus, subject received either a control block with 64 control trials and 20 test trials or an adaptation block with 64 adaptation trials and 20 test trials. The order of control and adaptation blocks over the sessions were balanced between subjects.

\section{Daia analysis}

Because the aim of this study was to examine whether hand pointing is influenced by saccadic adaptation, we conducted preliminary analyses to identify the three sessions with the greatest amount of eye adaption for each subject ${ }^{2}$. We then subjected hand pointing data from these sessions to the additional analyses described in the Results section.

\section{Results}

Figure 2 shows the mean saccade amplitudes and hand pointing amplitudes from the test trials after the control blocks and after the adaptation blocks, respectively.

${ }^{2}$ We selected ihree out of four sessions, because some subjects were not adapted in all four sessions. However, all six subjects were adapted in at least three sessions, i.e. significant shorter eye movements in test trials during the adaptation block than during the control block. 


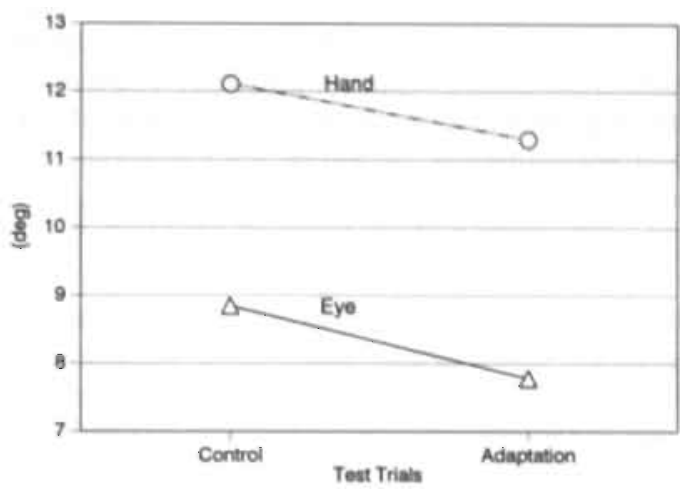

Figure 2. Mean end positions (deg) of eye and hand movements in test trials during the adaptation blocks and the control blocks. Both eye and hand movements are shorter following the control blocks.

Overall, amplitudes were shorter after the adaptation phase than after the control phase, $F(1,5)=7.7, p<.04$. There was no main effect found for type of movement (eye versus hand), $F(1,5)=2.9, p>.14$. Additionally, there was no interaction effect between type of movement and condition $F(1,5)<1$, indicating an equivalent effect of adaptation for eye and hand movements. Overall, amplitudes in the adaptation phase compared to the control phase were shortened from $8.88^{\circ 3}$ to $7.78^{\circ}$ for eye movements and from $12.11^{\circ}$ to $11.30^{\circ}$ for hand movements, equal to an adaptation level of $50 \%$ and $41 \%$ of the $2^{\circ}$ target step, respectively.

\section{Discussion}

The shorter hand movements in test trials during the adaptation blocks compared to those test trials during the control blocks shows that adaptive modification of the ocular motor system also affects hand-pointing movernents. This presence of transfer frem the ocular motor system to the skeletal motor system is consistent with the possibility that the two motor systems use a common signal to specify eye and arm localization (Nemire and Bridgeman, 1987).

Logicalily speaking, it can be argued that it was not the eye system that adapted in the present experiment, but the hand system, and, consequently, this hand adaptation was transferred to the eye system. However, there are several reasons which argue against this interpretation. Firstly, several researchers have described eye adaptation in experiments

\footnotetext{
'Although the target appeared at $10^{\circ}$ to the, right of fixation during the control block, the eye. movement was on the average $8.8^{\circ}$. However because the target disappeared at the onset of the saccade, no retinal information regarding the accuracy of the eye movement was available. Knowing this, the observed mean is consistent with the normal pattern of a primary eye movement, traveling approximately $90 \%$ of target amplitude.
} 
with no hand movements at all (e.g., Abrams et al., 1992; Miller et al., 1981; Semmlow et al., 1989), and, moreover, reported comparable adaptation values for the eye. No one, yet, on the other hand ${ }_{n}$ has described hand adaptation caused by eye-movement contingent target displacements, and with no visual feedback available from the hand. It could be logically argued that hand adaptation cannot and should not occur under such

circumstances. If subjects cannot see their hand and get no knowledge of results then there is no reason for the hand movement to adapt. Secondly, the hand system has been shown to have access to accurate information about target location even in circumstances where the perceptual system is misinformed--or is affected by an illusion (e.g., Abrams et al., 1990; Abrams \& Landgraf, 1990; Bridgeman et al., 1979; Goodale et al., 1986; Honda, $1985 ; 1990$ ). Why should the hand adapt when it has access to the final position after displacement? Finally, due to the phenomenon of saccadic suppression, adaptation happens at an unconscious level. Probably, the most important reason to assume that eye adaptation is influencing hand pointing is that we manipulated the eye error-signal and not the hand error-signal, i.e. the target jumped at the onset of the eye movement ${ }^{4}$.

A question that we cannot answer yet concerns the nature of the common mechanisms underlying saccade adaptation and hand motor control. At least two different. interpretations could be offered two explain the present findings. Firstly, the locus of the adaptation is in the perceptual system, and if so, it should affect any response. For instance, changes in the eye movements that people produce might affect the perceived visual directions of objects scanned with those eye movements, as suggested by Coren (1986). Thus, the perceived location of objects scanned while the eye was adapted should differ from that when the eye was in an unadapted state. Tests of this possibility have shown that the altered eye movements do not appear to distort visual metric judgments (McLaughlin et al., 1968). Secondly, the locus of the adaptation is in the motor system-but at a point common to several motor systems. That is, perception might still be veridical on the test trials, but the mapping between perceived locations and motor commands may be rearranged. One way to accomplish this would be for the adaptation to produce a change in a gain parameter (referred to as "parametric" adaptation). In this way the amplitude of an adapted saccade to a given target position might be some constant proportion of the amplitude of saccades to the same target before adaptation (McLaughlin, 1967). If this were occurring, then rearrangement within the oculomotor system could be passed on to the skeletal motor system via the common gain parameter. However, there is still some controversy regarding the extent to which the oculomotor adaptation is truly parametric (see Abrams et al., 1992; Frens \& van Opstal, in press). More work is needed to resolve this issue, but the answer may provide considerable insight into the common processes involved in generating both eye and hand movements.

\footnotetext{
'An alternative interpretation for the present findings could be that shortening of the hand position in the adaptation block is based on afferent information deriving from, the eye. However, there is some evidence which appears to be inconsistent with an afferent information interpretation. Firstly, such an interpretation would assume that the eye started to move first, while it is known from the literature that without time pressure, eye and hand start to move at about the same time (e.g.. Abrams et al., 1990). Secondly, several researchers have tried and failed to find a correlation between the error of gaze position and hand pointing position when the target disappeared at the moment of saccadic onset (e.g.. Prablanc et al., 1979).
} 


\section{References}

Abrams, R.A., Dobkin, R., \& Helfrich, M. (1992). Adaptive modification of saccadic eye movements. Journal of Experimental Psychology. Human Perception and Performance, 18, 922-933.

Abrams, R.A., \& Landgraf, J.Z. (1990). Differential use of distance and location information for spatial localization. Perception \& Psychophysics, 47, 349-359.

Abrams, R.A., Meyer, D.E., \& Komblum, S. (1990). Eye-hand coordination: Oculomotor control in rapid aimed limb movements. Journal of Experimental Psychology, Human Penception and Performance, 16, 248-267.

Bekkering, H., Adam, J.J., Kingma, H., Huson, A., \& Whiting, H.T.A. (1994). Reaction time latencies of eye and hand movements in single- and dual-task conditions. Experimental Brain Research, 97, 471-476.

Biguer, B., Jeannerod, M., \& Prablanc, C. (1982). The coordination of eye, head and arm movements during reaching at a single visual target. Experimental Brain Research ,46, 301-304.

Blouin, J., Bard, C., Teasdale, N., Paillard, J., Fleury, M., Forget, R., \& Lamarre, Y. (1993). Reference system for coding spatial information in normal subjects and a deafferent patient. Experimental Brain Research 93, 324-331.

Bridgeman, B., Henry, D., \& Stark, L. (1975). Failure to detect displacement of the visual world during saccadic eye movements. Vision Research, 15, 719-722.

Bridgeman, B., Lewis, S., Heit, G., \& Nagle, M. (1979). Relation between cognitive and motor-oriented systems of visual position perception. Journal of Experimental Psychology: Human Perception and Performance, 5, 629-700.

Coren, S. (1986). An efferent component in the visual perception of direction and extent. Psychological Review, 93, 391-4i0.

Deubel, H., Wolf, W., \& Hauske, G. (1986). Adaptive gain control of saccadic eye movements. Human Neurobiology, 5, 245-253.

Fischer, B., \& Rogal, L. (1986). Eye-hand coordination in man: A reaction time study. Biological Cybernetics, 55, 253-261.

Flanders, M., Helms Tillery, S.I., \& Soechting, J.F. (1992). Early stages in a sensorimotor transformation. Behavioral Brain Science, 15, 309-362.

Frens, M.A., \& Opstal van, A.J., (in press). Transfer of short-term adaptation in human saccadic eye movements. Experimental Brain Research.

Gielen, C.C.A.M., Heuvel van den, P.J.M., \& Gisbergen van, J.A.M. (1984). Coordination of fast eye and arm movements in a tracking task. Experimental Brain Research, 56, 154-161.

Goodale, M.A., Pelisson, D., \& Prablanc, C. (1986). Large adjustments in visually guided reaching do not depend on vision of the hand or perception of target displacement. Nature, 320, 748-750.

Graaf de, J.B. (1994). The initial direction of slow goal-directed arm movements: Deviations as a means to study spatial representation. PhD. thesis, Technical University Delft, Delft.

Henson, D.B. (1978). Corrective saccades: effects of altering visual feedback. Vision Research, 18, 63-67.

Honda, H. (1985). Spatial localization in saccade and pursuit eye movements conditions: A comparison of perceptual and motor measures. Perception and Psychophysics, 38, 41-46.

Honda, H. (1990). The extraretinal signal from the pursuit-eye-movement system: Its role in the perceptual and the egocentric localization systems. Perception \& Psychophysics, 48, 509-5I5.

Jeannerod, M. (1985). The neural and behavioural organization of goal-directed movements. Oxford, Oxford Psychology series, 15, 283.

Mather J.A., \& Fisk J.D. (1985). Orienting to targets by looking and pointing: Parallels and interactions in ocular and manual performance. Quarterly Journal of Experimental Psychology ,37A:315-338.

McLaughlin, S. (1967). Parametric adjustment in saccadic eye movements. Perception \& Psychophysics, 2, 359-362.

McLaughlin, S., Kelly, M., Anderson, R., \& Wentz, T. (1968). Localization of a peripheral target during parametric adaptation of saccadic eye movements. Perception \& Psychophysics, 4, 45-48.

Miller, J.M., Anstis, T., \& Templeton, W. (1981). Saccade plasticity: Parametric adaptive control by retinal feedback. Journal of Experimental Psychology: Human Perception and Performance, 7, 356-366.

Nemire, K., \& Bridgeman, B. (1987). Oculomotor and skeletal motor systems share one map of visual space. Vision Research, 27, 393-400.

Paillard, J. (1991). Motor and representational framing of space. In: J. Paillard (ed), Brain and space, (pp. 
163-182). Oxford, New York, Tokyo, Oxford University Press.

Prablanc, C., Echallier, J.F., Komilis, E., \& Jeannerod, M. (1979). Optimal response of eye and hand motor systems in pointing at a visual target: 1 . Spatio-temporal characteristics of eye and hand movements and their relationship when varying the amount of visual information. Biological Cybernetics, 35, 113-124.

Prablane C., Echallier J.F., Komilis E., \& Jeannerod, M. (1979). Optimal response of eye and hand motor systems in pointing at a visual target: I. Spatio-temporal characteristics of eye and hand movements and their relationship when varying the amount of visual information. Biological Cybernetics, 35, 113-124.

Prablanc, C., Pelisson, D., \& Goodale, M.A. (1986). Visual control of reaching movements without vision of the moving limb: I. Role of retinal feedback of target position in guiding the hand. Experimental Brain Research, 62, 293-302.

Semmlow, J.i., Gauthier, G.M., \& Vercher, J. (1989). Mechanisms of short-term saccadic adaptation. Journal of Experimental Psychology, Human Perception and Performance, 15, 249-258. 


\section{7 \\ Epilogue}

In the Introduction to the present thesis the idea was mooted, based on the existing literature, that distinct decisions are made about when eye and hand movements have to be produced and where eye and hand have to be directed, in the context of pointing to a visually presented target. It is sobering, in retrospect, to have to tell the reader who has followed the main line of the thesis to this point, that this proposition was, in any case, much too simplistic to have been true! A clear, mutual dependence of the two mechanisms has recently been shown by Abrams and Dobkin (1994a) in demonstrating that subjects are slower to look to a previously cued, than to an uncued, location - an elaboration of the typical inhibition of return effect for attentional oriented movements initially found by Posner and Cohen (1984) - in the context of overt, oriented eye movements. The findings of this thesis, reported in Chapter 3, further complicate the understanding of when and where decisions in visual targeting by showing that the when decisions for both eye and hand movements are closely related to response-selection mechanisms of where to move eye and hand. The notion of a reciprocal relation between when and where decisions was enhanced by the finding that occurrence of the interference effect augmentation of eye latencies when the eye movement is accompanied by a hand movement is dependent on the nature of the required task. That is, the interference effect was observed in the case that response-selection decisions of where to move were demanded, while no interference effect was observed when highly salient stimuli were presented. Highly salient stimuli, presumably, by-passes response-selection decisions and evoke "reflexive" saccadic eye movements (Engel, 1977). Both when and where mechanisms would seem to be inextricably involved in actions demanding eye-hand coordination.

\section{Temporal order}

Chapters 2 and 3 throw some new light on the temporal order of eye and hand movements in the context of pointing to a visually presented target. The generality of the eye-first, handsecond phenomenon is questioned by the absence of this typically observed serial order effect in some of the presented experiments. In experiments where, for instance, subjects were required to move to a large target region, or in case they knew in advance were the target would appear, the saccade was closely time-locked to the initiation of the limb movement. The actual movement order therefore may depend on the behavioural task involved, amongst others, the amount of uncertainty about the spatial location of the target. In fact, the findings that eye and hand movements could be initiated concurrently in response to visually presented target stimuli, suggests that there is little reason to believe that eye movements are an essential component of rapid, goal-directed limb movements. Only the secondary hand sub-movements 
seem to be produced mainly on the basis of visual feedback provided by the eye in order to guide the hand to the target region. (e.g., Abrams \& Pratt, 1993). Nevertheless, the complexity of the forthcoming response may demand a different amount of preparation time of eye and hand movements. That is, preparation time to construct an eye movement (e.g., specifying the desired spatial and temporal properties of the forthcoming response) is typically independent of accuracy constraints (e.g. Carpenter, 1988), while construction of hand movements depends heavily on the complexity of the forthcoming response (e.g., Christina et al., 1982; Fitts \& Peterson, 1964; Fischman, 1984; Sideaway, 1991; Sideaway et al., 1988).

\section{Common command}

The investigations - by means of a correlational approach - to the question whether eye and hand responses are initiated by one common or by different command signals, are disappointing. Very inconsistent results are apparent, leaving some serious doubts about the usefulness of a correlational approach in the study of eye-hand coordination when pointing to a visual target. The correlation values found between eye and hand RT latencies may have been non-informative because of the fact that processes in the human nervous system that immediately precede and allow for the execution of movements contain a deliberate random element (Carpenter, 1988, see also section 1.1).

Instead of the all-or-none question as to whether or not there is one common command to initiate eye and hand movements, the focus in this thesis was on whether or not the ocular and manual motor systems are related in terms of when the observer starts to move eye and hand and in terms of where the observer directs eye and hand in response to a visually presented target.

Fascinatingly, a relation between when mechanisms was found in Chapter 2 in the form of an interference effect; demonstrated by the finding of longer eye latencies in the situation where the saccadic eye movement was accompanied by an aimed hand movement relative to the situation where the eye was initiated alone to the presented target stimulus. Chapter 3 exploited the nature of the observed interference effect and suggested mechanisms concerned with the response-selection of the movements as the source of the interference effect. Particularly, response-selection mechanisms of where to move were found to be the source of the interference effect, clearly indicating the reciprocity between when and where mechanisms.

Chapter 6 reported an intriguing interaction between where mechanisms of the ocular and manual motor systems. An unconscious adaptation in the end position of the eye - by means of shortening the target amplitude at the moment that the eye started to move to the target - clearly influenced the end position of aimed hand movements. That is, hand movements in tesi trials were found to be shorter when the eye was adapted than when the eye was unadapted. Due to the fact that in these test trials the target disappeared at the onset of the eye movement, no secondary hand movements were evoked. Primary hand movements, presumably, are ballistic in nature, i.e. not modifiable once begun. The finding of a relation in end position of ballistic eye and hand movements seems to be consistent with the notion that the two motor systems share one visual map to specify eye and hand localization (e.g., Section 1.3.4). 
'Gap' effect

Saslow (1967) was the first to report that a temporal gap between fixation point offset and target stimulus onset results in shorter saccadic latencies than if the fixation point remains visible. The 'gap effect' has been attributed to oculomotor readiness (Saslow, 1967), general warning or preparation effects (Ross \& Ross, 1980; 1981), facilitated sensory processing (Reulen, 1984), facilitated attentional disengagement (e.g., Fischer, 1987; Fischer \& Breitmeyer, 1987; Mayfrank et al., 1986).

The recently more aptly overt oculomotor processes explanation (Kingstone \& Klein, 1993a, 1993b, Reuter-Lorenz, et al., 1991; Tam \& Stelmach, 1993; Tam \& Ono, 1994), assumes that during fixation, the oculomotor system is effectively locked or engaged on the fixation target and that voluntary shifts of fixation and reflexive glances toward novel objects are inhibited (e.g., Guitton et al., 1985). Extinguishing the fixation stimulus facilitates saccadic latencies by breaking the processes that maintain the eye directed at the fixation stimulus. Neurophysiological research suggested that the Superior Colliculus (SC), which forms part of a system that facilitates active visual fixation (e.g., Munoz \& Wurtz, 1992), is essential for the generation of short latency saccades that are produced in the gap paradigm (e.g., Munoz \& Wurtz, 1992; Schiller, Sandell \& Maunsell, 1987).

At first, the findings of aimed hand gap effects in this thesis seem to conflict with the overt oculomotor explanation in terms of SC mechanisms. However, Werner (1993) has recently reported neuronal activity in the primate $\mathrm{SC}$ before and during arm movements to visual targets, and there is more evidence that the SC is involved in all types of orienting movements towards external targets (Fries, 1984; 1985). Overall, the findings in this thesis of aimed hand gap effects in some experiments, and the absence of a gap effect for simple, non-oriented, manual keypress responses in another, support overt motor explanations. However, the facilitative effect of fixation point offset does not only occur for oriented, ocular responses but also for oriented, manual responses.

\section{Directions for future research}

Temporal order. The enormous variability in temporal organization of eye and hand movements shows us the complexity of the mechanisms underlying the decision of when to initiate coordinated eye-hand movements. Besides, pointing movements can be made independently of what kind of object is presented in the environment. A logical next step would be to manipuilate the what nature of the presented object, e.g., shape, size or orientation of the object, as well as to consider the question of what we are supposed to do with the object of interest (e.g., Jeannerod 1988; Rosenbaum, 1992). However, more complex movements, as for instance grasping an object, will demand at least two motor components. Firstly, a ballistic transport component to bring the hand near to the target location and, secondly, a grasp component to make contact with the object (e.g., Paulignan et al., 1991a; 1991b). An interesting question is whether the first transport component of the grasping movement can be considered as similar in nature to a rapid pointing movement (followed by an additional grasping component) or whether the motor systems involved in reaching and grasping movements can be considered as totally separate modules (e.g., Paulignan, 1991a; Jeannerod, 1986). 
Interference effect. The augmentation of saccadic eye latencies when they are accompanied by goal-directed hand movements points to the close relation between the two motor systems. However, it has to be noticed that the amount of interference in the dual-task condition - eye and hand - relative to the single-task condition - eye or hand - is rather low compared to two functionally independent tasks such as vocal and manual tasks (e.g., Pashler et al., 1993). It would be interesting to know whether the interference is relatively low because of the fact that eye and hand move to the same location in space. One way to investigate this question would be to employ anti-saccades, i.e., saccades away from the target stimulus, and normal aimed hand movements - or vice versa, saccades and anti-hand movements) in single- and dual-task conditions.

"The Gap effect". The gap experiments showed a possible link between fixated and oriented processes in a more general sense, i.e. not limited to the ocular motor system. Manual oriented movements are inhibited as well when the observer is actively fixating a stimulus. It would be meaningful to investigate whether a gap effect exists for all the orienting systems, i.e. for head and trunk movements towards a presented target stimulus, indicating the generality of the gap effect for all the motor systems.

Transfer of adaptaition. The finding of transfer of adaptation from the ocular to the manual motor system is consistent with the possibility that the two motor systems use a common signal to specify eye and arm localization. However, the nature of the common mechanisms could be interpreted at least at two different levels. Firstly, it might be that adaptation affects the perceptual processes of objects scanned with adapted eyes (Coren, 1986). Thus, the perceived location scanned while the eye is adapted differs from that when the eye is unadapted. Secondly, the changes in output may be explained by a change in gain parameter in the oculomotor output which is passed on to the skeletal motor output (see also Chapter 6). A possible way to clarify these two possibilities would be to require non-motoric responses of subjects in an adapted and unadapted state. If adaptation affects perceptual processes, nonmotoric responses would also be influenced by the adaption.

Studying motor behaviour. Spatially oriented behaviours form the core of people's ability to effectively interact with the physical world. The present thesis provides new insighis into fundamental perceptuo-motor mechanisms involved in coordinated eye and hand movements. Further determination of the questions outlined in this thesis will be invaluable in understanding daily human interactions with the immediate environment. In addition, it could provide a good framework for the understanding of natural movement disorders. Parkinsons patients, for instance, often have difficulty initiating rapid limb movements. A very intruiging question deriving directly from the research outlined above - is whether Parkinson's patients also have difficulties in initiating saccadic eye movements. A better understanding of the basic processes underlying spatially oriented behaviour in normal subjects could provide considerable insight into the assessment and treatment of perceptual-motor disorders. Further fundamental investigations into the temporal and spatial organization of eye and hand movements should, ultimately, lead to a comprehensive model in which all the processes that underlie spatially oriented behaviour can be understood. 


\section{References}

Abrams, R.A., \& Dobkin, R.S. (1994). The gap effect and inhibition of return: Interactive effects on eye movement latencies. Experimental Brain Research, 98, 483-487.

Abrams RA, Pratt J (1993) Rapid aimed limb movements: Differential effects of practice on component submovements. J of Mot Beh 25:288-298

Carpenter, R.H.S. (1988). Movements of the eyes. Pion, London.

Christina, R.W., Fischman, M.G., Vercruyssen, M.J.P., \& Anson, J.G. (1982). Simple reaction time as a function of response complexity: Memory drum theory revisted. Journal of Motor Behavior, 14, 301-321.

Coren, S. (1986). An efferent component in the visual perception of direction and extent. Psychological Review, 93, 391-410.

Engel, F.L. (1977). Visual conspicuity and selective background interference in eccentric vision. Vision Research, 14, 459-471.

Fischer, B. (1987). The preparation of visually guided saccades. Reviews of Physiology, Biochemistry and Pharmacology, 106, 1-35.

Fischer, B., \& Breitmeyer, B. (1987). Mechanisms of visual attention revealed by saccadic eye motions. Neuropsychologica, 25, 73-83.

Fischer, B., \& Ramsperger, E. (1984). Human express saccades: Extremely short reaction times of goal-directed eye movements. Experimental Brain Research, 57, 191-195.

Fischman MG (1984) Programming time as a function of number of movement parts and changes in movement direction. Journal of Motor Behavior, 16, 405-423.

Fries, W. (1984). Cortical projections to the superior colliculus in the macaque monkey: a retograde study using peroxidase. Journal of Comp Neurology, 230, 55-76.

Fries, W. (1985). Inputs from the motor and prennotor cortex to the superior colliculus in the rhesus monkey. Behavioural Brain Research, 18, 95-105.

Jeannerod, M. (1986). The formation of finger grip during prehension: A cortically mediated visuomotor pattern. Behavioural Brain Research, 19, 99-116.

Jeannerod, M. (1988). The neural and behavioural organization of goal-directed movements. Clarendon Press, Oxford

Kingstone, A. \& Klein, R. (1993a). Visual offset facilitate saccadic latency: Does pre-disengagement of visouspatial attention mediate this gap effect? Journal of Experimental Psychology: Human Perception and Performance, 19, 1251-1265.

Kingstone, A., \& Klein, R. (1993b). What are human express saccades? Perception \& Psychophysics, 54, 260-273. Mayfrank, L., Mobashery, M., Kimmig, H., \&. Fischer, B. (1986). The role of fixation and visual attention in the occurence of express saccades in man. European Archives of Psychiarry \& Neurolical Sciences, 235, 269-275.

Munoz, D.P., \& Wurt? R.H. (1992). Role of the rostral superior colliculus in active fixation and execution of express saccades. Journal of Neurophysiology, 67, 1000-1002.

Pashler, H., Hoffman, J., Carrier, M. (1993). Saccadic eye movements and dual-task interference. Quarterly Journal of Experimental Psychology, 46, 51-82.

Paulignan, Y., Mackenzie, C., Marteniuk, R. \& Jeannerod, M. (I991a). Selective perturbation of visual inpur during prehension movements. I. The effects of changing object position. Experimental Brain Research, 83, 502-512.

Paulignan, Y., Jeannerod, M., Mackenzie, C., \& Marteniuk, R. (1991a). Selective perturbation of visual input during prehension movements. 11. The effects of changing object size. Experimental Brain Research, 83, 513519.

Posner, M.I.P., \& Cohen, Y. (1984). Components of visual orienting. In H. Bouma \& D.G. Bouwhuis (Eds.). Attention and Performance X (pp. 531-556), Hillsdale, NJ:Erlbaum.

Reulen, J.P.H., (1984a). Latency of visually evoked saccadic eye movements: I. Saccadic latency and the facilitation model. Biological Cybernetics, 50, 251-263.

Reulen, J.P.H., (1984b). Latency of visually evoked saccadic eye movements: II. Temporal properties of the facilitation mechanism. Biological Cybernetics, 50. 263-271.

Reuter-Lorenz, P., Hughes, H., \& Fendrich, R. (1991). The reduction of saccadic latency by prior offset of the fixation point: An analysis of the gap effect. Perception \& Psychophysics, 49, 167-175. 
Rosenbaum, D.A., Vaughan, J., Barnes, H.J., \& Jorgensen, M.J. (1992). Journal of Experimental Psychology: Learning, Memory and Cognition, 18, 1058-1073.

Ross, L.E., \& Ross, S.M. (1980). Saccade latency and warning signals: Stimulus onset, offset, and change as warning events. Perception \& Psychophysics, 27, 263-271.

Ross, L.E., \& Ross, S.M. (1981). Saccade latency and warning signals: Effects of auditory and visual stimulus onset and offset. Perception \& Psychophysics, 29, 429-437.

Saslow M.G. (1967). Latency for saccadic eye movement. Journal of Optical Society of America, 57, 1030-1033.

Schiller, P.I., Sandell, J.H., \& Maunsell, J.H.R. (1987). The effect of frontal eye field and superior colliculus lesions on saccadic latencies in the rhesus monkey. Journal of Neurophysiology, 57, 1033-1049.

Sideaway B, Christina RW, Shea JB (1988) A movement constraint interpretation of the response complexity effect and programming time. In A Colley \& J Beechs (eds) Cognition and action in skilled behaviour. Amsterdam: North-Holland, pp 87-102.

Sideaway B (1991) Motor programming as a function of constraints on movement initiation. Journal' of Motor Behavior, 23, 120-130

Tam, W., \& Stelmach, L. (1993). Viewing behavior: Ocular and attentional disengagement. Perception \& Psychophysics, 54, 211-222.

Tam, W., \& Ono, H. (1994). Fixation disengagement and eye-movement latency. Perception \& Psychophysics, 56, 251-260.

Werner, W. (1993). Neurons in the primate superior colliculus are active before and during arm movements to visual targets. European Journal of Neuroscience, 5, 335-340. 


\section{Summary}

In order to interact effectively in the everyday world, man depends heavily on close coupling between perceptual information and motoric action. In order to produce aimed hand movements to a visual target, for example, it is necessary to accurately map visual-spatial information about the target onto an appropriate set of commands to the muscles required to reach for, or point to, the object of interest. Although humans are very accurate in their goal-directed behaviour, the mechanisms underlying looking and pointing are quite complex and much remains to be learned about them. The focus of this thesis is on the relation between the mechanisms involved in manual and oculomotor control. More specifically, attention is directed to the temporal (when) and spatial (where) decisions involved in both eye and hand movements.

Chapter 1 provides an introduction into the theoretical systems underlying the temporal and spatial organization of eye and hand. Firstly, observations about the temporal organization of eye and hand responses were denoted. While the consensus of most of the literature is that the eyes start to move towards the target before the hand, there are some studies which challenge this position suggesting that the eye-first, hand-second temporal order might have little to do with the provision of foveal information to guide the hand to the desired end position. Other studies have investigated the latency correlation between eye and hand movements concluding, in general, that such correlations are relatively small. Dual-task studies in which subjects are required to make eye or hand movements, separately, or simultaneously, to a visual target have also figured prominently in the literature. With respect to interference effects, the results have generally been inconsistent.

Secondly, a number of potential sources of spatial information which would enable the generation of saccadic eye and aimed hand movements have been suggested. Amongst these figure retinal information about the target (e.g., information about the location and movement of the object in the environment, about limb position and about the status of the ongoing movement) together with extra-retinal eye position information and proprioceptive hand position information which have to be well-matched in an unitary visual map in order to generate accurate eye and hand movements.

Chapter 2 reports on experiments in which dual-task methodology is employed to investigate whether eye and hand motor systems operate independently or whether they share processes with regard to decisions about when to produce the required output. Results showed that eye latencies were longer in the situation in which the eye was accompanied by an aimed hand movement relative to the situation in which the eye was initiated alone to the presented target stimulus. The finding that saccadic eye movements and button-press responses in the dual-task condition could be initiated without delay relative to the single-task conditions, supported a specific eye-hand coordination bottleneck explanation.

Chapter 3 reports experiments into the nature of the interference effect. This was shown not to be related to a specific temporal bottleneck, i.e. sharing of limited available processes at a specific point in time but, it was suggested, that the mechanisms concerned with response-selection of movements constitute the source of the interference effect.

Chapter 4 reports on experiments in which is investigated whether the "gap effect" shorter saccadic latencies in case of a temporal gap between fixation point offset and stimulus onset than if the fixation point remains visible - is also present for manual responses. A robust 
gap effect was found for aimed hand movements, independent of whether the hand moved alone or was accompanied by a saccadic eye movement. Also a small gap effect for choice keypress response was found but no gap effect for simple responses. These findings suggested an interpretation of the gap effect in terms of facilitation of spatially oriented responses.

Chapter 5 presents experiments in which the presence or absence of a gap effect for aimed hand movements and simple keypress responses is related to response-preparation processes or response-execution processes. The finding of robust gap effects for eye and aimed hand movements independent of response-preparation mechanisms (i.e. target uncertainty) was consistent with an inierpretation of the gap effect in terms of facilitation of response-execution processes associated with spatially oriented eye and hand movement responses.

Chapter 6 reports on experiments which investigated whether hand pointing is influenced by an adaptive modification of saccadic eye movements. Eye movements were shortened by an unconscious target displacement during the eye movement. The finding of shorter hand movements when the eye was adapted compared to when the eye was unadapted suggested such a transfer. This result was consistent with the interpretation that the eye and hand motor systems use a common signal to specify where to move.

Chapter 7 - the Epilogue - provides a synopsis of the experimental findings from this thesis in the context of the relevant literature. This led to the overall conclusion that new insights had been provided into fundamental perceptuo-motor mechanisms involved in coordinated eye and hand movements, which, ultimately, should lead to a comprehensive model in which all the processes that underlay spatially oriented behaviour can be understood. 


\section{Samenvatting}

Effectieve interactie met de ons omringende wereld vraagt om een nauwe koppeling tussen perceptuele informatie en motorische actie. Voor het produceren van gerichte handbewegingen naar een visueel doel is het bijvoorbeeld noodzakelijk dat we accuraat de beschikbare visueelruimtelijke informatie over het doel omzetten in een set van geschikte commando's naar de spieren. Deze commando's zijn noodzakelijk om te reiken of te wijzen naar het object van aandacht. Hoewel mensen erg accuraat zijn in hun doelgerichte bewegingen, zijn de mechanismen die ten grondslag liggen aan kijken en wijzen erg complex en dient er nog veel over geleerd te worden. Dit proefschrift richt zich op de relatie tussen mechanismen betrokken bij manuele en oculaire motorcontrole. De aandacht is specifiek gericht op temporele (wanneer) en ruimtelijke (waar) beslissingen die betrokken zijn bij zowel oog- als handbewegingen.

Hoofdstuk 1 biedt een introductie in de theoretische systemen die ten grondslag liggen aan de temporele en ruimtelijke organisatie van oog en hand. In de eerste plaats werden observaties over de temporele organisatie van oog en hand beschreven. Hoewel de consensus in de literatuur is dat de ogen beginnen te bewegen naar het doel voor de hand, werden er enkele studies besproken die deze opvatting doen wankelen, daarbij suggereren dat de oog-eerst, hand-daarna temporele orde weinig te doen heeft met het verstrekken van foveale informatic, mogelijkerwijs nodig om de hand naar de gewenste eindpositie te leiden. Andere studies hebben de correlatie tussen latentietijden van oog- en handbewegingen onderzocht en geconeludeerd werd dat deze over het algemeen relatief laag is. Dubbeltaakstudies waarin proefpersonen gevraagd worden om oog of hand apart of gelijktijdig te bewegen naar een visueel doel zijn ook prominent vertegenwoordigd in de literatuur. Met betrekking tot een eventuele interferentie tussen het opstarten van beide systemen zijn de resultaten inconsistent.

In de tweede plaats werden een aantal potentiële bronnen van ruimtelijke informatie beschikbaar voor de generatie van saccadische oogbewegingen en doelgerichte handbewegingen besproken. Geconcludeerd werd dat retinale informatie over het doel - bijvoorbeeld informatie over de locatie en beweging van het doel in de omgeving, informatie over ledemaatpositie alsmede over de status van de huidige beweging - samen met extra-retinale oogpositieinformatie en proprioceptieve handpositie-informatie nauwkeurig afgestemd dient te worden in een enkele visuele map om accurate oog- en handbewegingen te genereren.

Hoofdstuk 2 doet verslag van experimenten in welke de dubbeltaakmethode is gebruikt om te onderzoeken of oog- en handsystemen onafhankelijk opereren of dat beide systemen processen delen met betrekking tot beslissingen over wanneer de bewegingen te produceren. Resultaten lieten zien dat latentietijden van het oog langer zijn in een conditie waarin het oog werd vergezeld door een handbeweging dan in een conditie waarin het. oog alleen werd geïnitieerd naar het aangeboden doel. De bevinding dat saccadische oogbewegingen en druktoets-responsen in de dubbeltakkconditie geïnitieerd konden worden zonder vertraging relatief tot de enkeltaakconditie, ondersteunde de opvatting dat er sprake is van een specifieke "bottleneck" voor oog-hand coördinatie.

Hoofdstuk 3 doet verslag van experimenten naar de aard van dit interferentie-effect. Het effect bleek niet gerelateerd te zijn aan een specifiek, temporele "bottleneck", i.e., deling van 
gelimiteerd aanwezige processen op een specifiek punt in de tijd. Gesuggereerd werd dat mechanismen betrokken bij de response-selectie van de bewegingen de bron van het interferentie-effect bevatten.

Hoofdstuk 4 onderzoekt of het "gap effect" - kortere saccadische latentietijden indien er sprake is van een temporele "gap" tussen het verdwijnen van het oorspronkelijke doel van fixatie en het verschijnen van het nieuw te fixeren doel - ook voor manuele responses opgaat. De bevindingen van een robuust "gap effect" voor doelgerichte handbewegingen onafhankelijk van het feit of de hand alleen bewoog of vergezeld werd door een saccadische oogbeweging, een kleiner "gap effect" voor keuze-toetsresponsen en geen "gap effect" voor simpeletoetsresponsen zijn consistent met een interpretatie van het "gap effect" in termen van facilitatie van ruimtelijk, oriënterende responsen.

Hoofdstuk 5 presenteert experimenten in welke de aan- of afwezigheid van het "gap effect" wordt gerelateerd aan respons-preparatie-processen of respons-executie-processen. De bevinding dat een vereenvoudiging van preparatieprocessen door het verstrekken van informatie over de positie van het doel van de oog-en handbeweging niet tot een vermindering van het "gap effect" leidt, suggereert dat het effect gelokaliseerd is in de uitvoeringsfase van oog- en handbewegingen en niet in de preparatiefase.

Hoofdstuk 6 doet verslag van een experiment welke onderzocht of wijzen met. de hand wordt beìnvloed door een adaptieve verandering in saccadische oogbewegingen. Oogbewegingen werden ingekort door een onbewuste doelverandering gedurende de oogbeweging. De bevinding van kortere handbewegingen indien het oog geadapteerd was vergeleken met wanneer het oog ongeadapteerd was, geeft aan dat de oog- en handmotorsystemen informatie delen met betrekking tot beslissingen over waar naar toe te bewegen.

Hoofdstuk 7 - de Epiloog - biedt een synopsis van de experimentele bevindingen van dit proefschrift in de context van de relevante literaturur. Dit leidde tot de algemene conclusie dat nieuwe inzichten zijn verkregen in de fundamentele, perceptuele-motorische mechanismen betrokken bij coördinerende oog- en handbewegingen, welke uiteindelijk moeten leiden tot een coherent model waarin alle processen die ten grondslag liggen aan ruimtelijke georiënteerde gedragingen begrepen kunnen worden. 


\section{Curriculum Vitae}

Harold Bekkering was born in Oldenzaal on the 19th of October 1965. Upon completion of secondary school at the Nederrijn College, Arnhem (Atheneum) in 1985, he began his study in Psychology at the University of Nijmegen. In Februari 1990 he graduated with a Master's degree in Experimental Psychology. During the years 1989 and 1990 he worked at the TNO Human Factors Research Institute in the area of visual-vestibular interactions. In 1991 he started his Ph.D. research at the University of Limburg in the field of eye-hand coordination. Part of this research was conducted at the Washington University, St. Louis, USA. From May 1995, he will be employed as a "Wissenschafticher Mitarbeiter" at the Max-Planck-Institute for Psychological Research in Munich (Germany). 
